University of Tennessee Health Science Center UTHSC Digital Commons

\title{
$5-2014$
}

\section{Adenosine Production Is Essential for Closing the Critical Period of Cortical Plasticity}

Rachel A. Chassan

University of Tennessee Health Science Center

Follow this and additional works at: https://dc.uthsc.edu/dissertations

Part of the Medical Neurobiology Commons

\section{Recommended Citation}

Chassan, Rachel A. , "Adenosine Production Is Essential for Closing the Critical Period of Cortical Plasticity" (2014). Theses and Dissertations (ETD). Paper 42. http://dx.doi.org/10.21007/ etd.cghs.2014.0049.

This Thesis is brought to you for free and open access by the College of Graduate Health Sciences at UTHSC Digital Commons. It has been accepted for inclusion in Theses and Dissertations (ETD) by an authorized administrator of UTHSC Digital Commons. For more information, please contact jwelch30@uthsc.edu. 


\title{
Adenosine Production Is Essential for Closing the Critical Period of Cortical Plasticity
}

\begin{abstract}
Sensory inputs from the external world are represented as highly organized systems in the adult brain for effective adaptation to the environment. At the cortical level, this organization is referred to as cortical maps. The establishment of cortical maps begins with early life experiences during the critical period, a brief period during development of heightened sensitivity to sensory stimuli. During this time, organization of cortical maps is plastic and highly subject to change through passive sensory experience. As an animal matures, the critical period closes and changes to cortical maps occur less freely. The cellular mechanisms of cortical map plasticity in adults remain unknown, and are thought to underlie perceptual learning and memory. Based on work in brain slices, it has previously been suggested that the mechanism of cortical map plasticity in the primary auditory cortex (Al) occurs at thalamocortical (TC) synapses in the form of synaptic plasticity. As the critical period closes, adults develop an adenosinedependent presynaptic gate that prevents TC synaptic plasticity from occurring. By removing the adenosine gate, synaptic plasticity is able to be induced at mature TC synapses. In the present study, I examined if adenosine-dependent presynaptic gating at TC synapses underlies Al cortical map plasticity in live animals. Through genetic deletion of adenosine machinery at TC synapses, I found that cortical map plasticity at Al in adult mice could be induced through passive tone exposure, which was only thought to work during the auditory critical period.
\end{abstract}

\section{Document Type}

Thesis

\section{Degree Name}

Master of Science (MS)

\section{Program}

Biomedical Sciences

Research Advisor

Stanislav S. Zakharenko M.D. Ph.D.

Keywords

Adenosine, Cortical Plasticity, Critical Period, Primary Auditory Cortex

\section{Subject Categories}

Medical Neurobiology | Medicine and Health Sciences 


\title{
Adenosine Production Is Essential for Closing the Critical Period of Cortical Plasticity
}

\author{
A Dissertation \\ Presented for \\ The Graduate Studies Council \\ The University of Tennessee \\ Health Science Center
}

In Partial Fulfillment

Of the Requirements for the Degree

Master of Science

From The University of Tennessee

By

Rachel A. Chassan

May 2014 
Copyright (C) 2014 by Rachel A. Chassan. All rights reserved. 


\section{DEDICATION}

This is dedicated to my family. 


\section{ACKNOWLEDGEMENTS}

I would like to express my sincere gratitude to Dr. Stanislav Zakharenko for his mentorship and support over the past three years. Thank you for taking me on as a student, offering your guidance, and for your understanding throughout this process. I would also like to acknowledge the rest of my committee members, Dr. Jay Callaway, Dr. Leta Nutt, and Dr. Jian Zuo for being so encouraging and agreeing to join my committee on such short notice. You each have given me insightful comments and suggestions that have helped me write this thesis.

My sincere thanks goes to Dr. Jay Blundon for introducing me to neuroscience and research; you have been a great teacher all of these years. I appreciate your patience and taking the time to teach me electrophysiology. I would also like to acknowledge Dr. JJ Westmoreland for his expertise in molecular biology. I thank my fellow lab members: Dr. Ildar Bayazitov, Dr. Sungkun Chun, Dr. Prakash Devaraju, Dr. Fei Du, Dr. Laurie Earls, Dr. Olena Filchakova, Dr. Brett Teubner, and Jing Yu.

Last but not least I would like to thank my parents for their continuous love and support. 


\begin{abstract}
Sensory inputs from the external world are represented as highly organized systems in the adult brain for effective adaptation to the environment. At the cortical level, this organization is referred to as cortical maps. The establishment of cortical maps begins with early life experiences during the critical period, a brief period during development of heightened sensitivity to sensory stimuli. During this time, organization of cortical maps is plastic and highly subject to change through passive sensory experience. As an animal matures, the critical period closes and changes to cortical maps occur less freely. The cellular mechanisms of cortical map plasticity in adults remain unknown, and are thought to underlie perceptual learning and memory. Based on work in brain slices, it has previously been suggested that the mechanism of cortical map plasticity in the primary auditory cortex (AI) occurs at thalamocortical (TC) synapses in the form of synaptic plasticity. As the critical period closes, adults develop an adenosinedependent presynaptic gate that prevents TC synaptic plasticity from occurring. By removing the adenosine gate, synaptic plasticity is able to be induced at mature $\mathrm{TC}$ synapses. In the present study, I examined if adenosine-dependent presynaptic gating at TC synapses underlies AI cortical map plasticity in live animals. Through genetic deletion of adenosine machinery at TC synapses, I found that cortical map plasticity at AI in adult mice could be induced through passive tone exposure, which was only thought to work during the auditory critical period.
\end{abstract}




\section{TABLE OF CONTENTS}

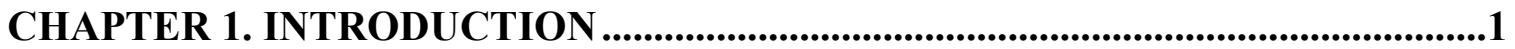

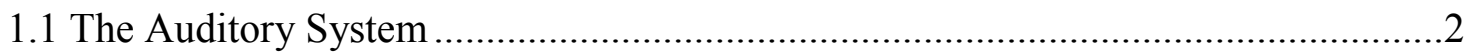

1.2 The Primary Auditory Cortex..........................................................................

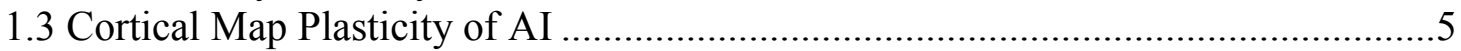

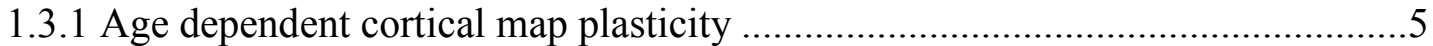

1.3.2 Cellular mechanisms of cortical map plasticity.......................................... 7

1.4 Presynaptic Gating of Synaptic Plasticity at Thalamocortical Synapses ................8

CHAPTER 2. MATERIALS AND METHODS.......................................................11

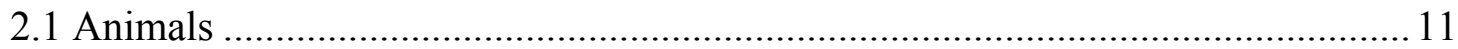

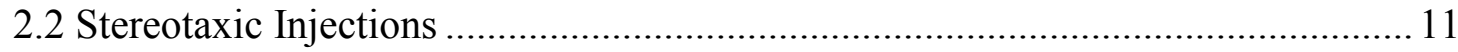

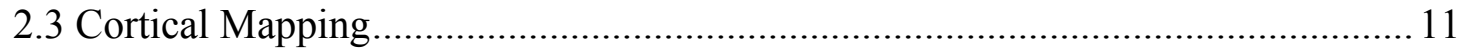

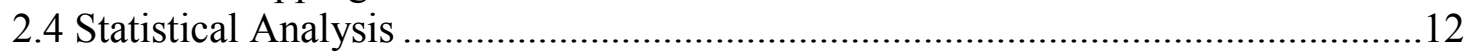

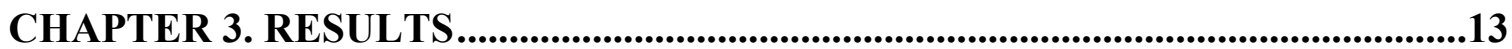

3.1 Deletion of $\mathrm{A}_{1} \mathrm{Rs}$ in Mature Mice Allows Cortical Plasticity through

Passive Tone Exposure......................................................................................... 13

3.2 Deletion of Cd73 in Mature Mice Allows Cortical Plasticity through

Passive Tone Exposure............................................................................................ 13

3.3 Disordered Tonotopic Distribution in $A_{1} R^{f l f l}$ Mice with a Conditional

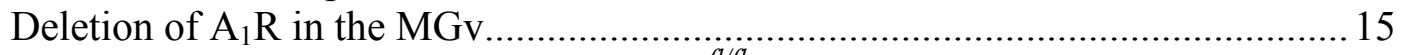

3.4 Disordered Tonotopic Distribution in $A_{1} R^{f l f l}$ Mice with a Conditional

Deletion of $\mathrm{A}_{1} \mathrm{R}$ in the $\mathrm{ACx}$ and Uninjected $A_{1} R^{f l f l}$ Mice.................................. 18

CHAPTER 4. DISCUSSION ............................................................................................20

4.1 Cortical Plasticity in $\mathrm{A}_{1} \mathrm{R}$ and $\mathrm{Cd} 73$ General Knockouts................................... 21

4.2 Cortical Plasticity in the $\mathrm{A}_{1} \mathrm{R}$ Conditional Knockout........................................ 22

4.3 New Approaches to Create a Conditional Knockout/Knockdown Mouse .............. 23

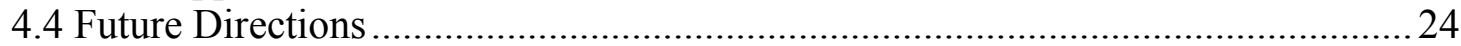

4.4.1 Development of thalamocortical gating of cortical plasticity ......................... 24

4.4.2 Lasting changes to the AI cortical map .......................................................2. 25

4.4.3 Improved learning with cortical map plasticity........................................26

4.4.4 Presynaptic gating and acetylcholine modulation .......................................26

4.4.5 Mechanisms of cortical plasticity for other primary sensory cortices..............2 27

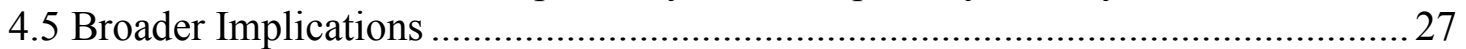

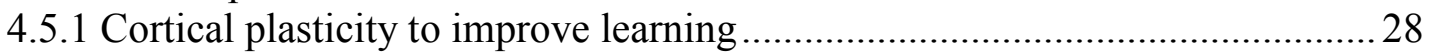

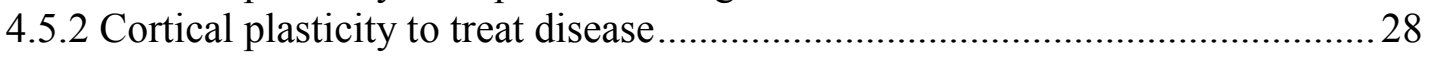

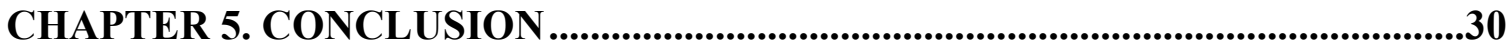

LIST OF REFERENCES ............................................................................................

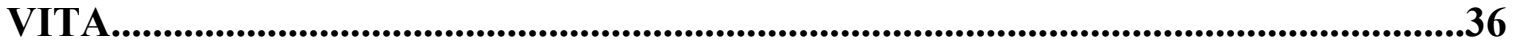




\section{LIST OF FIGURES}

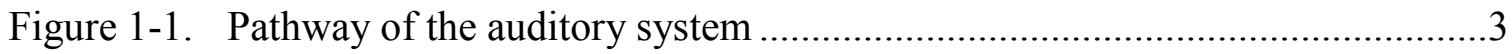

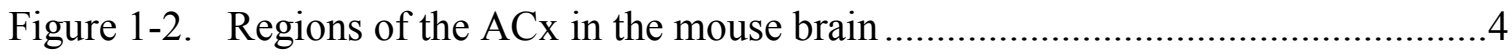

Figure 1-3. Means of inducing cortical plasticity in adults .....................................6

Figure 1-4. A model of adenosine-dependent presynaptic gating at a mature

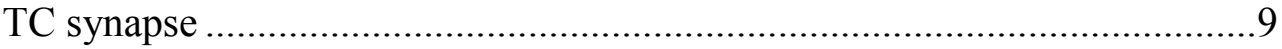

Figure 3-1. $\quad A_{1} R$ deletion allows cortical map plasticity in mature mice to be induced by passive tone exposure .......................................................... 14

Figure 3-2. Cd73 deletion allows cortical map plasticity in mature mice to be induced by passive tone exposure ........................................................ 16

Figure 3-3. Disrupted tonotopic organization of cortical maps in mice with a conditional deletion of $\mathrm{A}_{1} \mathrm{R}$ in the $\mathrm{MGv}$

Figure 3-4. Disrupted tonotopic organization of cortical maps in mice with a conditional deletion of $\mathrm{A}_{1} \mathrm{R}$ in the $\mathrm{ACx}$ and uninjected $A_{1} \mathrm{R}^{f l / f l}$ mice 


\section{LIST OF ABBREVIATIONS}

$\begin{array}{ll}\text { ACh } & \text { Acetylcholine } \\ \text { ACx } & \text { Auditory cortex } \\ \text { AI } & \text { Primary auditory cortex } \\ \text { BF } & \text { Best frequency } \\ \text { LTD } & \text { Long term depression } \\ \text { LTP } & \text { Long term potentiation } \\ \text { MGv } & \text { Ventral medial geniculate nucleus } \\ \text { NB } & \text { Nucleus basalis } \\ \text { TC } & \text { Thalamocortical }\end{array}$




\section{CHAPTER 1. INTRODUCTION}

Throughout their lifetime, animals must navigate and adapt to the ever-changing external environment. The brain must quickly gauge incoming sensory stimuli, then process and store important information about the stimuli in the form of perceptual memory. It remains unknown where and how perceptual memory is stored in the brain. Primary sensory cortices (vision, touch, and audition) undergo changes in their neural circuitry as animals are exposed to different sensory experiences (Takesian and Hensch, 2013). Although primary sensory cortices have been studied to better understand their role in detection and analysis of their respective external sensory input, it has been recently suggested that they may play a much greater role in cognitive functions and are thought to be the substrates of sensory memory (Merzenich and Sameshima, 1993; Weinberger, 2012).

Primary sensory cortices are well-defined areas of the neocortex organized as cortical maps. These maps are highly ordered to match the incoming projections from the sensory periphery (Barnes and Finnerty, 2010). They have topographic representations of the sensory exterior (Buonomano and Merzenich, 1998). For example, similar sensory inputs, such as sounds of a similar frequency, will activate adjacent cells in the primary auditory cortex. This organization provides shorter, more efficient connections to process sensory information across cortical layers and between brain regions (Schreiner and Winer, 2007).

Cortical maps are investigated for studying perceptual learning and memory because they undergo changes in response to the sensory environment throughout the lifetime of an animal (Kaas, 1991; Rauschecker, 2009; Schreiner and Polley, 2014). The mechanisms for this cortical map plasticity are unknown. The neural circuitry of cortical maps is not permanent, but its mechanisms for plasticity differ between young and adult animals. Cortical map plasticity in young animals was first discovered to occur in critical periods during development when cortical maps are established (Wiesel and Hubel 1965). During this period, neuronal circuits underlying the cortical maps easily undergo plasticity due to heightened sensitivity to sensory stimuli (Hensch 2005; Takesian and Hensch 2013). This readily allows circuit re-wiring and shaping of the topographic organization that is dependent upon sensory experience (Barnes and Finnerty, 2010). Upon maturation and closing of the critical period, cortical connections are more stable. Re-shaping of the cortical map is still possible but must be specially modulated, therefore occurring less easily.

Not much is known about the cellular basis for the differences in cortical map plasticity between young and adult animals. Young animals have profound sensitivity to external stimuli and undergo cortical map plasticity to create a broad representation of the sensory environment. Adults respond to their environment differently, altering the induction of cortical map plasticity that is believed to underlie learning and memory (Merzenich and Sameshima, 1993; Barnes and Finnerty, 2010). I am interested in elucidating the cellular mechanisms leading to auditory memory formation in the brain. I 
am therefore focusing on cortical map plasticity in the primary auditory cortex of mature mice to better understand the storage of auditory perceptual memories.

\subsection{The Auditory System}

The auditory system is responsible for processing incoming sound stimuli and their features, such as pitch, location, intensity, and spectrotemporal patterns. In rodents, cortical responses to sound develop around postnatal day (P) 11 due to the onset of hearing (Froemke and Jones, 2012). The auditory pathway begins with the stimulation of hair cells by sound waves in the cochlea of the inner ear. This stimulation travels through the vestibulocochlear nerve (cranial nerve VIII) to the cochlear nucleus of the brainstem. These projections then lead to the inferior colliculus of the midbrain, followed by the medial geniculate body (MGB) of the thalamus (Ma and Suga, 2009). The thalamus then projects to various regions of the auditory cortex (ACx), including layer $3 / 4$ of the primary auditory cortex (AI) (Figure 1-1). Much of these subcortical projections mature by $\mathrm{P} 12$, after which is the onset of the auditory critical period that allows for cortical map plasticity before these pathways stabilize during P20-P25 (de Villers-Sidani, 2007; Froemke and Jones, 2012).

\subsection{The Primary Auditory Cortex}

The ACx in mice consists of five regions that are thought to have distinct functions in auditory processing (Figure 1-2). Non-primary fields do not have organized receptive fields and do they undergo experience-dependent cortical map plasticity (Schreiner and Winer, 2007; Ma and Suga, 2009; Schreiner and Polley, 2014), both of which are unique features to AI. The cortical map of AI has a topographic organization referred to as tonotopy, spatial organization of favored sound frequencies (Hackett et al., 2011). Tonotopy begins at the cochlea where neighboring regions have the greatest response to pure tones of a similar frequency, arranged from high to low frequencies. This tonotopic organization is maintained through primary (lemniscal) projections to the ventral division of the medial geniculate body (MGv) of the thalamus ( $\mathrm{Hu}, 2003$; $\mathrm{Ma}$ and Suga, 2009) which give rise to tonotopy of the AI cortical map (Hackett et al., 2011).

The AI cortical map ranges from low to high frequencies in a caudal to rostral orientation (Hackett et al., 2011). In a mouse, this extends from around $5 \mathrm{kHz}$ to $35 \mathrm{kHz}$ (Hackett et al., 2011). Lemniscal projections from the MGv create finely tuned receptive fields in AI providing distinct boundaries from other $\mathrm{ACx}$ regions that are broadly tuned (Ma and Suga, 2009). Primary auditory receptive fields are tuned to both frequency and intensity of acoustic stimuli. A frequency that elicits the greatest response by cells in a certain region is known as the best frequency (BF) (Guo et al., 2012). Cortical maps can be constructed by determining the BF for neighboring regions across AI. Tonotopic maps can also be formed using the characteristic frequency $(\mathrm{CF})$, a cell's greatest response to a frequency at the lowest intensity (Oswald et al., 2006; Carcea and Froemke, 2013). 


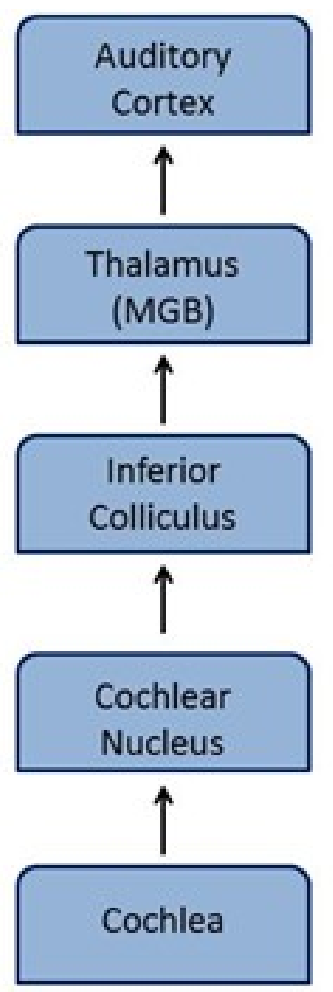

Figure 1-1. The pathway of the auditory system. 


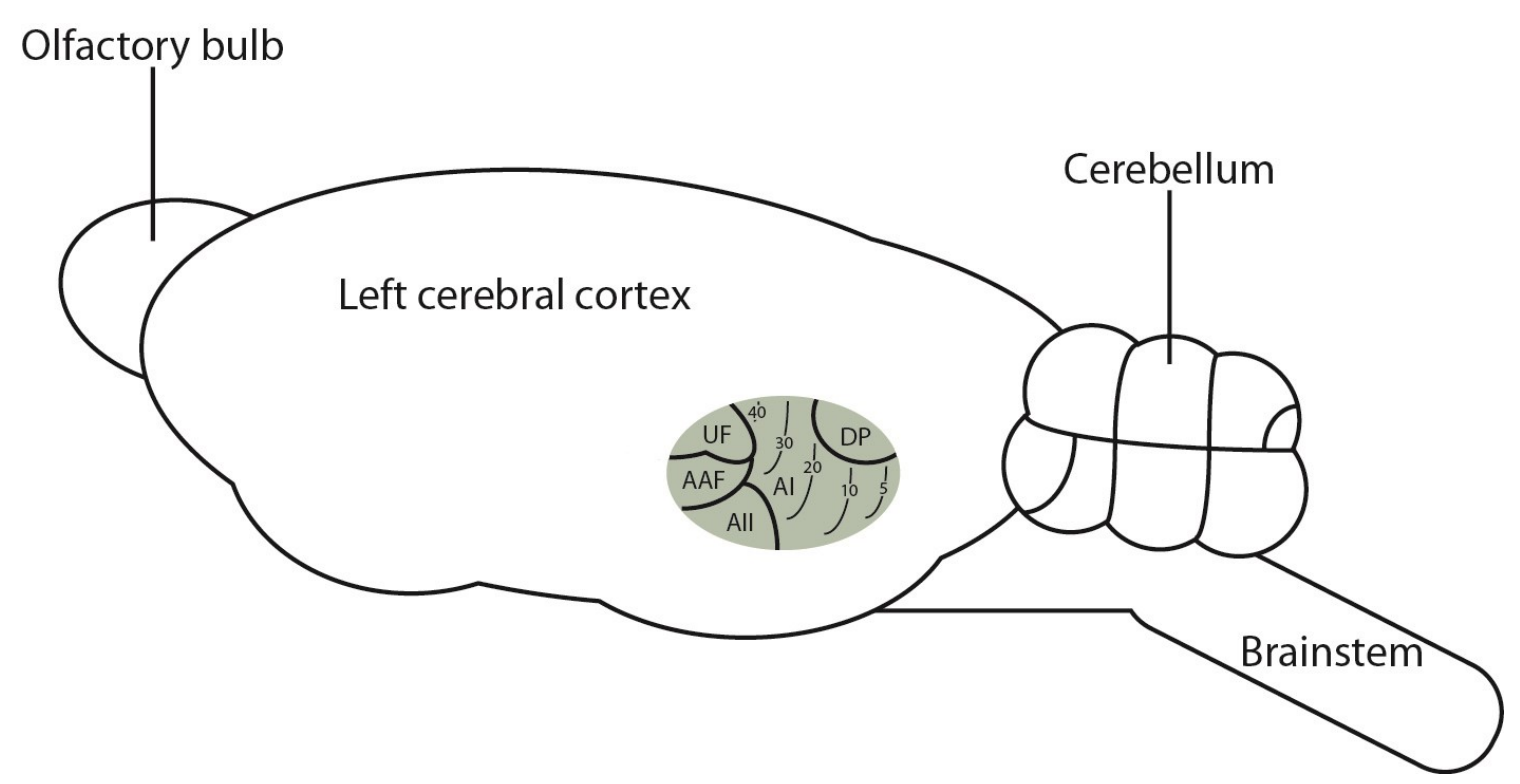

Figure 1-2. Regions of the $A C x$ in the mouse brain.

Lateral view of a mouse brain with the $\mathrm{ACx}$ and its field arrangement in grey, including the tonotopic organization of best frequencies across the primary auditory cortex (AI). Numbers indicate best frequencies in kHz. UF, ultrasonic field; AAF, anterior auditory field; AII, second auditory cortex; DP, dorsal posterior field. Not drawn to scale. Adapted with permission from John Wiley \& Sons Ltd. Geissler DB and G Ehret (2004) Auditory perception vs. recognition: representation of complex communication sounds in the mouse auditory cortical fields. Eur J Neurosci 19:1027-1040. 


\subsection{Cortical Map Plasticity of AI}

Map plasticity at AI can alter auditory processing, affecting sound localization, response intensity and timing, and frequency distribution (Schreiner and Polley, 2014). However, changes to the AI tonotopic map have been the most widely studied. Normal tonotopic maps have an even distribution of BFs across the AI region of the brain, meaning no frequency has a significantly larger representation than another. Plasticity induction can create shifts in the BFs causing the representation of one frequency to expand into a larger area of the cortical map. As described in all primary sensory cortices, plasticity in the AI cortical map is experience-dependent and is thought to differ mechanistically as a function of the animal's age.

\subsubsection{Age dependent cortical map plasticity}

Mice start with a poorly organized AI and develop a typical tonotopic map during the auditory critical period, with a full range of represented BFs (Keuroghlian and Knudsen, 2007). Yet throughout this time, the tonotopic map is highly sensitive to auditory stimuli from the environment and shifts in BF can easily be induced through passive sound exposure (de Villers-Sidani et al., 2007; Schreiner and Polley, 2014). Enriching the environment of an immature mouse by exposing it to a repeated pure tone within the first three days of the critical period can lead to expansion of AI that responds best to the frequency of that tone (Zhang et al., 2001; de Villers-Sidani et al, 2007). This expansion can become permanent and often lasts past the critical period through adulthood.

Enriching the environment of mice with a mature AI does not result in plasticity and has no effect on their already established tonotopy (Keuroghlian and Knudsen, 2007). It was therefore thought that cortical map plasticity is "lost" and does not occur in adults. However, recent experiments showed that in mature mice, cortical map plasticity does occur, just not passively (Takesian and Hensch, 2013). A frequency must become behaviorally relevant and important in the environment of a mouse to generate plasticity (Figure 1-3) (Keuroghlian and Knudsen, 2007; Carcea and Froemke, 2013). An adult mouse must attend to a frequency through associative learning or modulation by acetylcholine (ACh), dopamine, or norepinephrine (NE) for cortical map changes to occur (Figure 1-3).

Behavioral tasks in animal models have linked BF expansion in AI to better task performance that requires learning skills and memory formation (Reed et al., 2001; Bieszczad and Weinberger, 2012). Positive and negative reinforcement have both been shown to induce changes in tuning of the mature AI cortical map (Weinberger, 2005; Polley et al., 2006; Keuroghlian and Knudsen, 2007). ACh is released from the nucleus basalis (NB) as an animal becomes attentive to the acoustic stimulus that is paired with a foot shock or food reward, making it behaviorally novel. The NB receives information on the importance of a stimulus from limbic and paralimbic systems, and relays that information to the cortex through widespread cholinergic projections (Kilgard and 


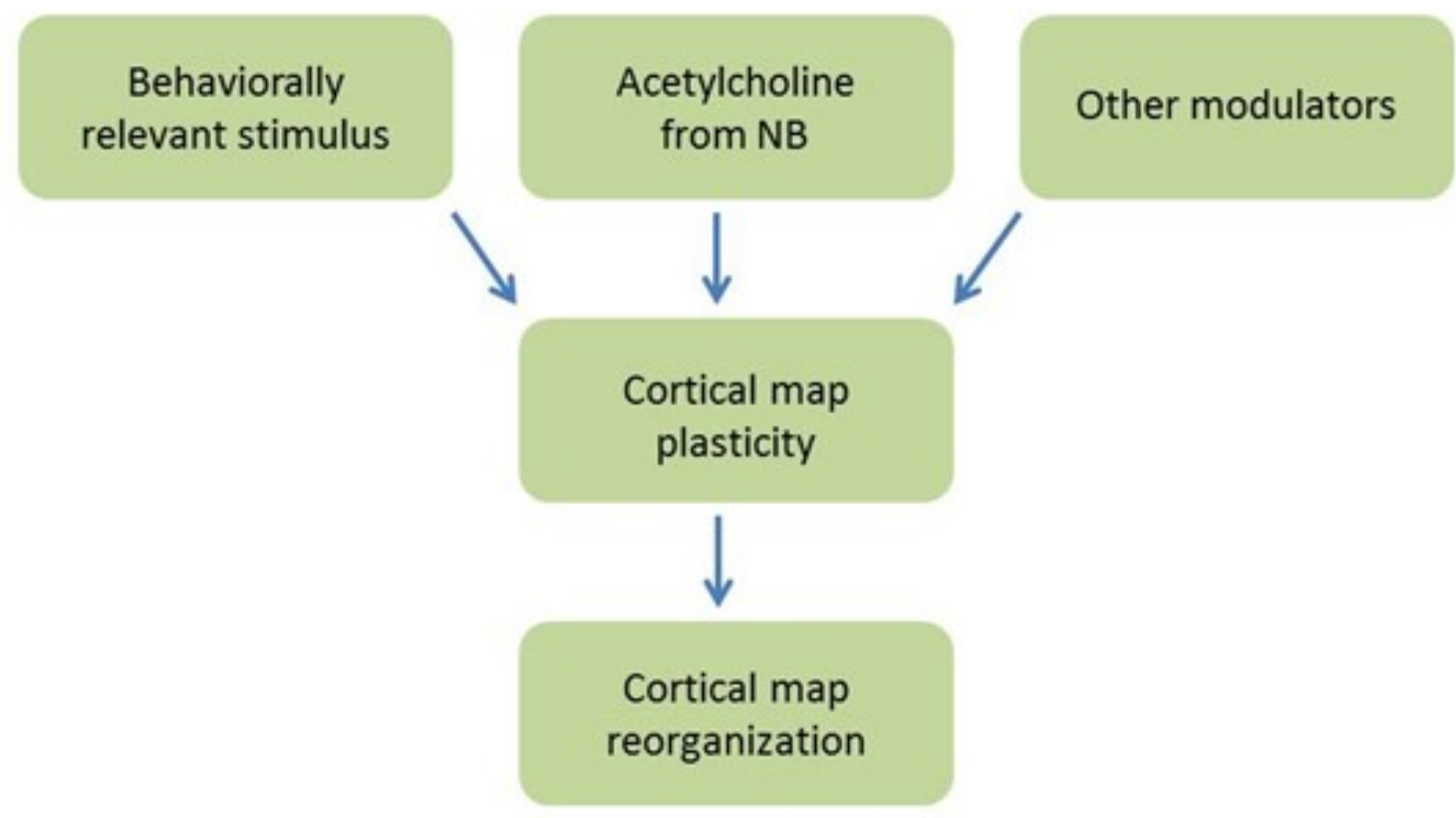

Figure 1-3. Means of inducing cortical plasticity in adult mice.

Adapted with permission from Elsevier. Kilgard MP (2005) Cortical map reorganization without cholinergic modulation. Neuron 48(4):529-530. 
Merzenich, 1998). Electrical stimulation of the NB paired with a tone mimics behavioral reinforcement to induce cortical map plasticity and reorganization towards the frequency of that tone (Kilgard and Merzenich, 1998; Froemke et al., 2007).

\subsubsection{Cellular mechanism of cortical map plasticity}

While the organization of tonotopic maps is understood, there is still much unknown about the underlying cellular mechanisms of plasticity that result in cortical restructuring. Many theories identify possible sources that control critical period plasticity and its closure, such as development of stable synaptic connections or molecular factors that limit plasticity, but they often fail to address mechanisms of plasticity past the critical period (Takesian and Hensch, 2014).

One prevailing hypothesis is that experience dependent plasticity at sensory cortices is the result of cortical circuitry modification in the form of synaptic plasticity, specifically long-term potentiation (LTP) and long-term depression (LTD) (Buonomano and Merzenich, 1998; Rauschecker, 1999; Malenka and Bear, 2004; Barnes and Finnerty, 2010). LTP and LTD are forms of Hebbian learning that provide the underlying mechanisms of memory storage through destabilization of neuronal connections and changing the strength of responses at glutamatergic synapses (Bliss and Collinridge, 1993; Schreiner and Polley, 2014). LTP strengthens synapses with a rapid, highfrequency stimulation that produces a rise in receptors to the postsynaptic density through calcium second messengers (Bliss and Collinridge, 1993). LTP results in faster postsynaptic activation and depolarization. The mechanism of LTD is also calcium dependent. A weak, slow stimulation results in removal of receptors from the postsynaptic density to weaken the synaptic activation (Malenka and Bear, 2004). LTP and LTD are possible mechanisms to describe bidirectional changes in the tonotopic map as responses to frequencies strengthen and weaken.

The cortex consists of complex circuitry with connections between its six layers and other regions of the brain. In the auditory field, there is an ongoing debate about the cellular site of synaptic plasticity resulting in cortical map plasticity. Thalamocortical (TC) synapses, from the MGv to L3/4 neurons of AI, were originally promising sites of synaptic plasticity that lead to changes in the cortical map (Blundon and Zakharenko, 2013). However, these synapses were soon overlooked, as synaptic plasticity at TC synapses could not be induced upon maturation. Repetitive stimulation for synaptic plasticity induction at mature TC synapses causes a depression in glutamate release (Oswald et al., 2006). LTP and LTD can easily be induced at TC synapses in younger animals, but the same induction does not produce any synaptic plasticity in adults (Crair and Malenka, 1995). Therefore, corticocortical synapses of AI soon became an attractive site of synaptic plasticity (Froemke et al., 2007; Carcea and Froemke, 2013). However, plasticity at corticocortical synapses does not follow the same developmental trajectory as cortical map plasticity. LTP and LTD can be induced at corticocortical synapses of the ACx throughout the lifetime of an animal (Blundon and Zakharenko, 2013) and this does not account for the cortical map plasticity differences between young and adult animals. 
I hypothesize that TC synapses, not corticocortical synapses, are the cellular sites of synaptic plasticity that lead to changes in the AI cortical map. This hypothesis was driven by consideration that the critical period for plasticity at TC synapses occurs at a similar time point in development as the critical period for cortical map plasticity. Based on recent work we now know that mature TC synapses do not lose their ability to undergo LTP or LTD, but instead develop a presynaptic gating mechanism that must be released to produce bidirectional synaptic plasticity in adults, described below

(Figure 1-4) (Blundon et al., 2011; Chun et al., 2013). TC synapses may therefore serve as the cellular source of in vivo cortical reorganization and sensory memory storage.

\subsection{Presynaptic Gating of Synaptic Plasticity at Thalamocortical Synapses}

Previous work suggests that cortical map plasticity between young and mature animals is different due to the development of a presynaptic gating mechanism that regulates postsynaptic plasticity at TC synapses (Figure 1-4) (Blundon and Zakharenko, 2013). This was demonstrated in vitro using acute (freshly made) TC slices that preserve the connections from the MGv to the ACx. In brain slices from adult mice, Blundon et al. (2011) used 2 different ways to induce LTD: conventional electric stimulation of TC projections and 2-photon glutamate uncaging of TC inputs on L3/4 cortical neurons. This latter technique mimics endogenous glutamate release by stimulating an exogenous "caged" form of glutamate at the synapse with two-photon light activation, thereby avoiding presynaptic stimulation (Pettit et al., 1997). Electric stimulation failed to induce LTD, consistent with the notion of the critical period. However, 2-photon uncaging in the same slices induced a robust LTD. The same result was obtained for TC LTP (Chun et al., 2013). By inducing LTD/LTP bypassing presynaptic terminals, this provided new evidence that synaptic plasticity at mature TC synapses is not lost but rather became gated with age. This gating apparently is presynaptic (i.e. MGv) in nature.

ACh release from the NB is a known contributor to cortical map plasticity in mature animals (Kilgard and Merzenich, 1998). It is known that pairing a sound with activation of the NB is sufficient to induce cortical map plasticity in adults (Kilgard and Merzenich, 1998). Therefore, if TC synapses are the cellular site of cortical map plasticity, ACh must be sufficient to release the presynaptic gate for TC LTP and LTD. Using two-photon imaging, further experiments showed that cholinergic activation of the muscarinic receptor $\mathrm{M} 1\left(\mathrm{M}_{1} \mathrm{Rs}\right)$ paired with electric stimulation of $\mathrm{tC}$ projections is sufficient to induce LTD (Blundon et al., 2011). Glutamate release at TC synapses is no longer depressed and can sufficiently activate postsynaptic calcium sensitive, group I metabotropic glutamate receptors (mGluRs) (Blundon et al., 2011). Cholinergic modulation was also required for induction of LTP at TC synapses (Chun et al., 2013).

Further experiments in slices showed that the activation of $\mathrm{M}_{1}$ Rs inhibits activity of adenosine, which is a well-known negative regulator of glutamate release at excitatory synapses. One possible mechanism for adenosine effect on glutamatergic synapses is through activation of the adenosine 1 receptor $\left(A_{1} R\right)$ leading to presynaptic 


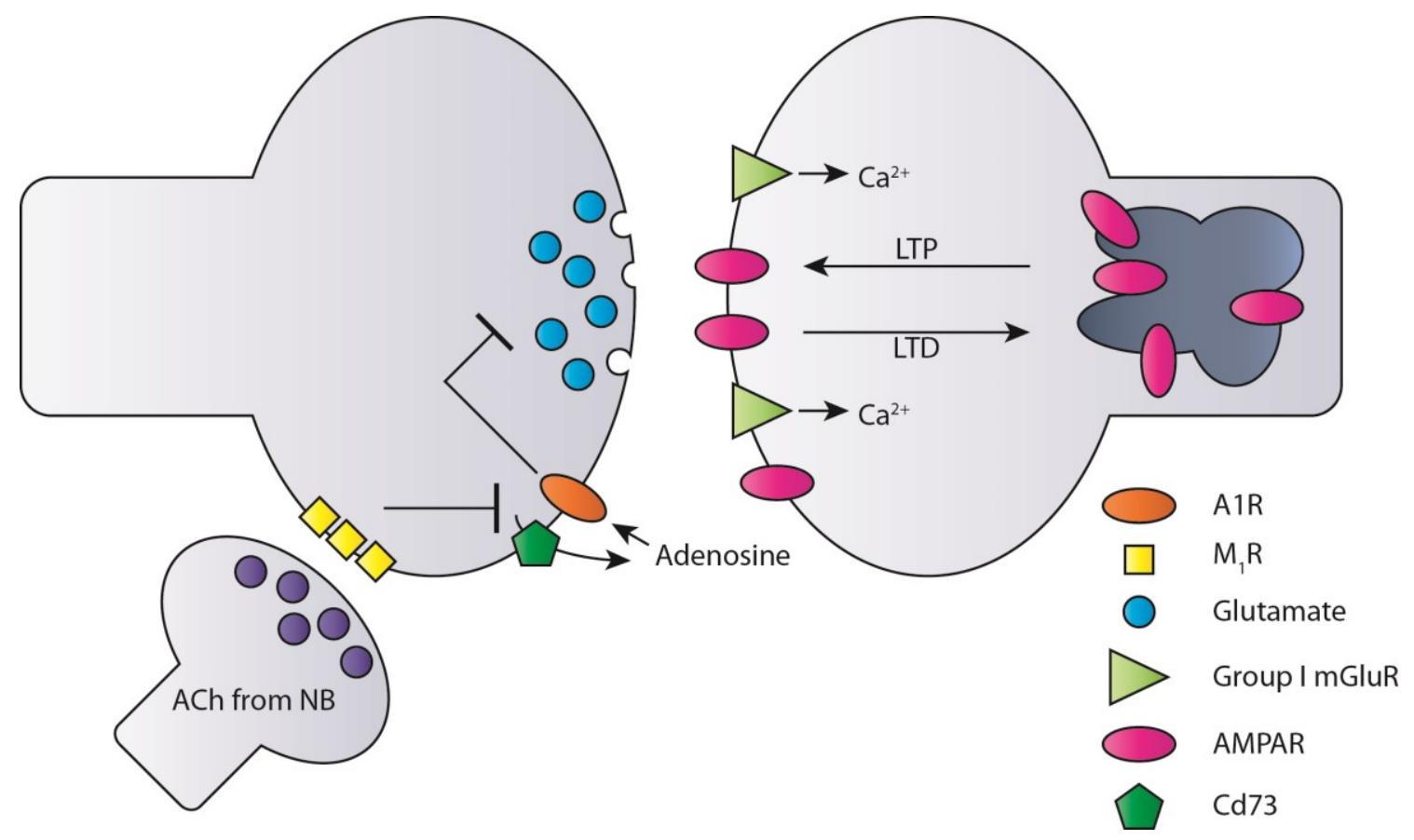

Figure 1-4. A model of adenosine-dependent presynaptic gating at a mature TC synapse.

Adenosine is released from the presynaptic cell and through a negative feedback mechanism, binds to presynaptic $A_{1}$ Rs to inhibit glutamate release. Inhibition of glutamate release prevents the induction of postsynaptic LTP and LTD. Presynaptic gating is released when the function of adenosine is inhibited by activation of $\mathrm{M}_{1}$ Rs from $\mathrm{ACh}$ input from the NB; therefore glutamate release is no longer diminished. There is now enough glutamate to activate group I mGluRs for an increase in intracellular $\mathrm{Ca}^{2+}$ and induction of LTP/LTD. Adapted with permission from The Journal of Neuroscience. Blundon JA, IT Bayazitov, Zakharenko SS (2011) Presynaptic gating of postsynaptically expressed plasticity at mature thalamocortical synapses. J Neurosci 31(44):16012-16025. 
hyperpolarization and reduction in calcium conductance (Dais et al., 2013). Adenosine is a co-neurotransmitter released at TC synapses that acts through a negative feedback mechanism to inhibit presynaptic release of neurotransmitter (Blundon and Zakharenko, 2013). Inhibition of adenosine activity at mature TC synapses in vitro allows for LTP and LTD induction without cholinergic modulation (Blundon et al., 2011; Chun et al., 2013). Therefore, adenosine activity may serve as the presynaptic gate that gradually inhibits glutamate release and prevents induction of synaptic plasticity in the adult brain.

The development of adenosine machinery may lead to mechanistic differences for the induction of cortical map plasticity in young and mature animals. Without functioning adenosine, ACh modulation should not be necessary to induce adult cortical map plasticity. Adenosine is produced by the dephosphorylation of adenosine triphosphate (ATP) that is broken down into adenosine monophosphate (AMP). AMP is converted into adenosine by the enzyme 5'-ectonucleotidase (Cd73). Although there are other enzymes that produce adenosine, $\mathrm{Cd} 73$ is responsible for the majority of adenosine production in the brain (Kulesskaya et al., 2013).

I therefore hypothesize that adenosine-dependent presynaptic gating at mature TC synapses is the cellular mechanism responsible for closing the critical period AI cortical plasticity. The aim of this study is to determine if disabling adenosine machinery in the auditory thalamus can extend or abolish the critical period and induce cortical map plasticity in AI of mature mice. To disable functioning adenosine I used mice with a general knockout of $\mathrm{A}_{1} \mathrm{R}\left(A_{1} R^{-/}\right)$or the adenosine producing enzyme 5'Ectonulceotidase $\left(C d 73^{--}\right)$. To further test this hypothesis, we created conditional knockout mice by injecting an AAV-hSynapsin-Cre vector into the auditory thalamus of $A_{1} R^{f l / f l}$ mice. Passively enriching the environment of mature $A_{1} R^{-/-}$and $C d 73^{-/-}$mice was enough to induce cortical shifts towards a new BF, whereas $A_{l} R^{\text {fl/fl }}$ did not develop normal tonotopic organization. 


\section{CHAPTER 2. MATERIALS AND METHODS}

\subsection{Animals}

Use of animals and all experimental procedures were performed under the approval of the Institutional Animal Care and Use Committee of St. Jude Children's Research Hospital. C57BL/6 wild-type mice (The Jackson Laboratory), $A_{1} R^{-/}$mice (Johansson et al., 2001), $C d 73^{-/-}$mice (Thompson et al., 2004), and $\mathrm{A}_{1} \mathrm{R}$ homozygous floxed mice $A_{1} R^{f l f l}$ (Scamell et al., 2003) of both sexes were used in cortical mapping experiments. All mice were backcrossed to the C57BL/6 background. Ages of the mice ranged from P35 to P90, before any high frequency hearing loss can occur in C57BL/6 (Willott, 1986). All mice were housed in a ventilated sound attenuation chamber where they received food and water ad libitum and maintained a 12:12 hour light:dark cycle.

\subsection{Stereotaxic Injections}

The adeno-associated virus AAV2/9-hSynapsin.Hi.GFP.Cre.WPRE.SV40 (Synapsin-Cre) was purchased from UPenn Vector Core $\left(1.57 \times 10^{\wedge} 13 \mathrm{IFU} / \mathrm{ml}\right)$. The virus was separated into $10 \mu \mathrm{l}$ aliquots and frozen at $-80^{\circ} \mathrm{C}$. Synapsin-Cre was injected into the ventral medial geniculate nucleus (MGv) of $A_{1} R^{f l f l}$ mice. Mice at 6 weeks old were anesthetized with $2-3 \%$ isoflurane in pure oxygen (1.0-1.5\% maintenance) and then head fixed in a stereotaxic device to open the skull and drill two small craniotomies. An individual aliquot was thawed and 40-400nl of virus was pressure injected over a 15 minute period using a metal cannula (28 gauge; Plastics One). The following coordinates for the MGv were measured from bregma: (1) anteroposterior, $-3.0 \mathrm{~mm}$; mediolateral, $2.0 \mathrm{~mm}$; dorsoventral, $3.1 \mathrm{~mm}$; (2) anteroposterior, $-3.5 \mathrm{~mm}$; mediolateral, -2.28 ; dorsoventral, $3.2 \mathrm{~mm}$. The following coordinates for the $\mathrm{ACx}$ were measured from bregma: (1) anteroposterior, $2.4 \mathrm{~mm}$; mediolateral, $-4.7 \mathrm{~mm}$; dorsoventral, $0.8 \mathrm{~mm}$. The cannula was left in place for 5 minutes after the injection, and then slowly retracted. Mice were given approximately 2-3 weeks to recover then used for cortical mapping.

\subsection{Cortical Mapping}

Mice spent two weeks in the chambers exposed to a sound or no sound protocol. Mice exposed to sound were continuously played a repeated train of 5 tones from an overhead speaker $(5 \mathrm{~Hz}$ train, $50 \mathrm{~ms}$ tone duration separated by a $20 \mathrm{~ms}$ period, each train separated by a $1 \mathrm{~s}$ period of silence). The frequency of these tones was either $7 \mathrm{kHz}$ or $11.4 \mathrm{kHz}$, calibrated to $70 \mathrm{~dB}$ SPL. Mice exposed to the no sound protocol were left in the chamber with no sound enrichment.

Cortical mapping was performed 0 to 5 days after the two weeks of sound or no sound exposure. Mice were anesthetized using sodium pentobarbital $(50 \mathrm{mg} / \mathrm{kg})$ and chlorprothixene $(0.2 \mathrm{mg})$, and further received supplemental doses of sodium 
pentobarbital $(25 \mathrm{mg} / \mathrm{kg})$ when needed. The mice remained head fixed while the ACx of the left hemisphere was exposed and dura was removed. Extracellular responses were recorded from $\mathrm{L} 3 / 4$ of the $\mathrm{ACx}$ (350-450 $\mu \mathrm{m}$ from the pial surface) using expoxylitecoated tungsten microelectrodes $(2.0 \mathrm{M} \Omega$ at $1 \mathrm{kHz} ; \mathrm{FHC})$. Frequency responses were measured with randomly presented tone pips of variable frequency ( 4.3 to $46 \mathrm{kHz}$ in 0.1 octave increments, $20 \mathrm{~ms}$ duration, $5 \mathrm{~ms}$ raised cosine onset/offset ramps, $0.5 \mathrm{~s}$ inter-trial interval) and level (0-70 dB SPL in 10dB increments) delivered from a free field electrostatic speaker (Tucker-Davis Technologies) placed $10 \mathrm{~cm}$ from the contralateral ear. Spike responses to tone pips were amplified with an RA4PA fiber optic preamplifier, filtered (high pass $=250 \mathrm{~Hz}$, low pass $=5000 \mathrm{~Hz}$ ), and digitized with an RZ6 real time processor (TDT). TDT System 3 software (OpenEx) generated the sound stimuli and response acquisition and storage.

The primary auditory field (AI) was determined by its caudal-to-rostral tonotopy surrounded by sites of poorly tuned receptive fields. For sites considered as AI, the best frequency (BF) was measured as the tone frequency that evoked the greatest number of spike responses at all sound levels. Cortical maps were created by determining the $\mathrm{BF}$ from 30-50 sites per mouse, each site separated by $50-100 \mu \mathrm{m}$. Only short latency $(<10$ $\mathrm{ms})$ spikes were analyzed as tone-evoked responses using TDT System 3 software (OpenEx) for BFs combined into bins of 0.22 octaves. All sites that were considered to be outside of AI were omitted from data analysis.

\subsection{Statistical Analysis}

Data are represented as the percentage of the area A1 responding to best frequencies collected in 0.22 octave bins. Percentage data were analyzed by two-way ANOVA (factored by frequency and by sound exposure protocol). If the ANOVA was shown to be significant, a Tukey post hoc multiple comparison procedure was used to make pairwise comparisons of means. Differences in mean data were considered significant if the P-value less than 0.05 . 


\section{CHAPTER 3. RESULTS}

\subsection{Deletion of $A_{1} R s$ in Mature Mice Allows Cortical Plasticity through Passive Tone Exposure}

We sought to determine whether presynaptically gated synaptic plasticity at TC synapses is the cellular source of cortical plasticity in adults. By removing the function of adenosine, expression of LTD and LTP at TC synapses may lead to cortical plasticity in adults without cholinergic modulation. We used WT and $A_{1} R^{-/-}$mice that matured beyond the critical period (mature mice) and exposed them to two weeks in a chamber enriched with a repeated train of $7 \mathrm{kHz}$ tones (70 dB SPL) or an identical chamber with no additional sound exposure. They were then taken for cortical mapping. Recordings were performed approximately $350-450 \mu \mathrm{m}$ from the pial surface, which corresponds to the L3/4 cortical layer.

We observed clear tonotopic organization of AI in WT mice $(n=5)$ with an even distribution of BFs ranging from 4 to $35 \mathrm{kHz}$ (Figure 3-1a). As reported previously, there was no difference in the tonotopic organization of AI from the passive, sound exposed mature WT mice $(\mathrm{n}=5)$ (Figure 3-1c) (Kilgard and Merzenich, 1998). Furthermore, $A_{1} R^{-/-}$mice from the no sound environment $(\mathrm{n}=5)$ did not undergo plasticity and had no changes to the tonotopic distribution of AI compared to WT mice ( $p$ $=0.892$ ) (Figure 3-1b and d). However, mice that underwent repeated sound exposure to a train of $7 \mathrm{kHz}$ tones did have changes to their cortical maps. $A_{1} R^{-/}$sound exposed mice $(\mathrm{n}=5)$ underwent shifts in $\mathrm{BF}$ towards $7 \mathrm{kHz}$ leading to a $39.7 \% \pm 5.8 \%$ area of AI that responded best to $7.9 \mathrm{kHz}$ tones compared to WT $(21.3 \% \pm 5.8 \%, \mathrm{p}=0.028, \mathrm{n}=5)$ and $A_{1} R^{-/}$mice exposed to no sound $(19.4 \% \pm 2.4 \%, \mathrm{p}<0.001)$ (Figure 3-1b and d). There was also a $34.04 \% \pm 2.3 \%$ increase the area of AI that responded to $5.5 \mathrm{kHz}$ in $A_{1} R^{-/}$sound mice compared to WT sound exposed $(17.39 \% \pm 6.84 \%, \mathrm{p}=0.041)$ and $A_{1} R^{-/}$ no sound mice $(13.3 \% \pm 6.53 \%, \mathrm{p}<0.001)$. This also led to a significant decrease in the area of AI from $A_{1} R^{-/}$sound exposed mice that responded to higher frequency tones, 23.6 $\mathrm{kHz}$ and $34.1 \mathrm{kHz}$, compared to $A_{1} R^{-/}$mice exposed to no sound ( $\mathrm{p}=0.005$ for $23.6 \mathrm{kHz}$, $\mathrm{p}<0.001$ for $34.1 \mathrm{kHz})$.

\subsection{Deletion of Cd73 in Mature Mice Allows Cortical Plasticity through Passive Tone Exposure}

As a next step, we wanted to test whether a reduction in adenosine production would have the same effect on cortical plasticity. We tested mature WT and $C d 73^{-/}$to determine if they underwent cortical map plasticity to passive tone exposure. These mice underwent the two-week exposure to the continuous train of $11.4 \mathrm{kHz}$ tones (70 dB SPL) or no sound exposure, followed by cortical mapping.

As seen in previously in WT sound exposed $(\mathrm{n}=4)$, there was no significant difference in the area of AI that responded to the $11.4 \mathrm{kHz}$ compared to WT mice that 

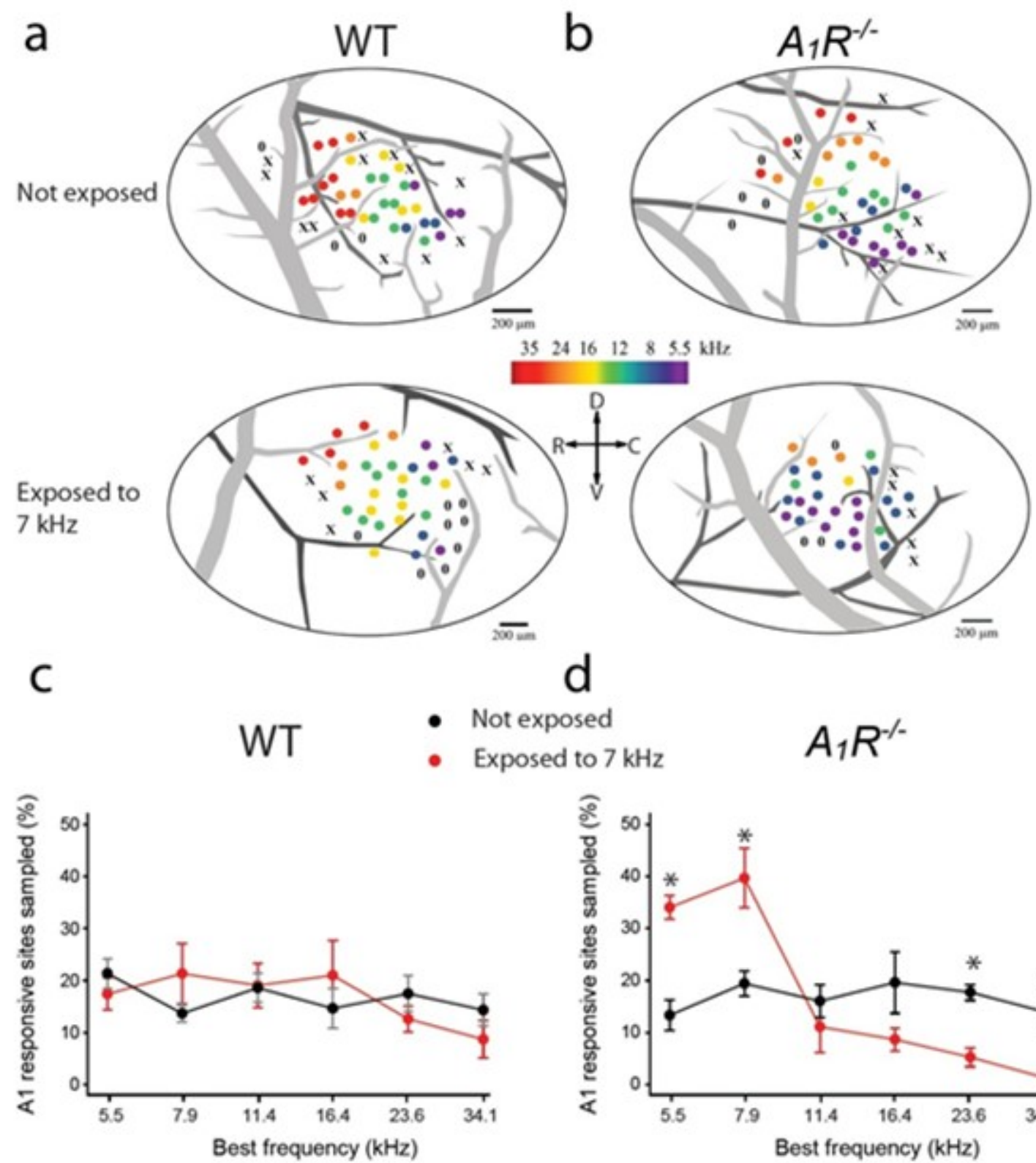

- $\begin{aligned} & \text { Not exposed } \\ & \text { Exposed to } 7 \mathrm{kHz}\end{aligned} A_{1} R^{-/-}$

Figure 3-1. $\quad A_{1} R$ deletion allows cortical map plasticity in mature mice to be induced by passive tone exposure.

$(\mathrm{a}, \mathrm{b})$ Representative cortical maps of AI from one WT (a) and one $A_{1} R^{-/-}(\mathrm{b})$ mouse exposed to no sound enrichment (top) and mice exposed to a repetitive $7 \mathrm{kHz}$ tone (bottom). The color of each circle represents the BF measured at that site. Null symbols represent unresponsive sites and "X"s refer to sites located outside of AI based on response latency and poor tuning. Light gray depicts the rhinal vein and dark gray depicts the cerebral artery. $\mathrm{R}$, rostral; D, dorsal; $\mathrm{C}$ caudal; V ventral. (c,d) The percentage of responsive recording sites in AI as a function of BFs in both WT (c) and $A_{1} R^{-/-}$(d) mice that are sound exposed to $7 \mathrm{kHz}$ and unexposed mice $* \mathrm{p}<0.05$. 
underwent no sound enrichment $(\mathrm{n}=5)$ (Figure 3-2c). These mice had an even tonotopic distribution regardless of the sound exposure protocol (Figure 3-2a). Mature $C d 73^{-/-}$ mice that underwent no sound exposure $(n=5)$ did not develop any changes to their tonotopic map and had an even distribution of BFs similar to WT mice $(\mathrm{p}>0.05)$ (Figure 3-2b and d). Adult $C d 73^{-/-}$mice exposed to the $11.4 \mathrm{kHz}$ tone $(\mathrm{n}=5)$ sound enrichment underwent a $41.35 \% \pm 11.42 \%$ expansion in the area of AI that responded best to the 11.4 $\mathrm{kHz}$ frequency compared to WT mice exposed to sound $(22.25 \% \pm 6.64 \%, \mathrm{p}=0.025)$ and $C d 73^{-/}$mice exposed to no sound $(17.47 \% \pm 4.01 \%, \mathrm{p}=0.002)$ (Figure 3-2b and d). $C d 73^{-/-}$mice have reduced adenosine production allowing them to retain cortical plasticity through passive learning as adults

\subsection{Disordered Tonotopic Distribution in $A_{1} R^{f l / f l}$ Mice with a Conditional Deletion of $A_{1} R$ in the MGv}

Because $A_{1} R^{-/-}$and $C d 73^{-/}$mice are general knockouts, it was important for us to show that adenosine machinery specifically at TC synapses is the source of presynaptic gating that regulates cortical plasticity. We therefore produced conditional knockouts of $\mathrm{A}_{1} \mathrm{R}$ using adult mice with a homozygous floxed $\mathrm{A}_{1} \mathrm{R}$ receptor $\left(A_{1} R^{f l f l}\right)$ and injected with AAV-hSynapsin-Cre to the $\mathrm{MGv}$. With $\mathrm{A}_{1} \mathrm{R}$ removed exclusively from thalamic neurons that innervate AI, these mice underwent the passive sound protocols and spent two weeks exposed to a repeated $11.4 \mathrm{kHz}(70 \mathrm{~dB}$ SPL) train or a no sound environment.

$A_{1} R^{f l f l}$ mice with conditional deletion of $\mathrm{A}_{1} \mathrm{R}$ in the $\mathrm{MGv}$ that were exposed to the no sound environment $(n=5)$ had disorganized tonotopic maps (Figure 3-3a). These mice had an uneven distribution of BFs. They had greatest responses to $6.2 \mathrm{kHz}$ and 8.9 $\mathrm{kHz}$ with almost no responses to higher frequencies (Figure 3-3b). In $A_{1} R^{f l f l}$ unexposed mice, $31.68 \% \pm 10.56 \%$ area of AI responded best to $6.2 \mathrm{kHz}$ whereas only $15.5 \% \pm$ $3.07 \%(\mathrm{p}=0.04)$ of AI cortical maps responded to this frequency from injected $A_{1} R^{f l / f l}$ mice exposed to sound. There was also a significant increase in the area that responded to $8.9 \mathrm{kHz}(32.66 \% \pm 4.32 \%)$ in unexposed $A_{1} R^{f l f f l}$ mice, compared to AI of the sound exposed mice $(14 \% \pm 3.82 \% \mathrm{p}=0.024)$.

After being exposed to $11.4 \mathrm{kHz}, A_{1} R^{f l f l}$ had an significant expansion of the region that responded best to $12.8 \mathrm{kHz}$ representing $35.6 \% \pm 6.93 \%(\mathrm{n}=5)$ of the area of AI compared to the no sound $A_{1} R^{f l f l}$ mice $(11.94 \% \pm 7.06 \%, \mathrm{p}=0.005)$ (Figure 3-3b). There was also a $24.6 \% \pm 9.14 \%$ increase in the region that responded to $18.5 \mathrm{kHz}$, which was significantly larger than $A_{l} R^{f l f l}$ no sound mice $(5.54 \% \pm 4.67 \%, \mathrm{p}=0.021)$. Because the control not exposed to sound $A_{1} R^{f l / f l}$ mice did not have an even tonotopic distribution, it is difficult to make meaningful comparisons the $A_{1} R^{f l f f l}$ with Cre injected to the MGv that underwent the sound enrichment protocol. 

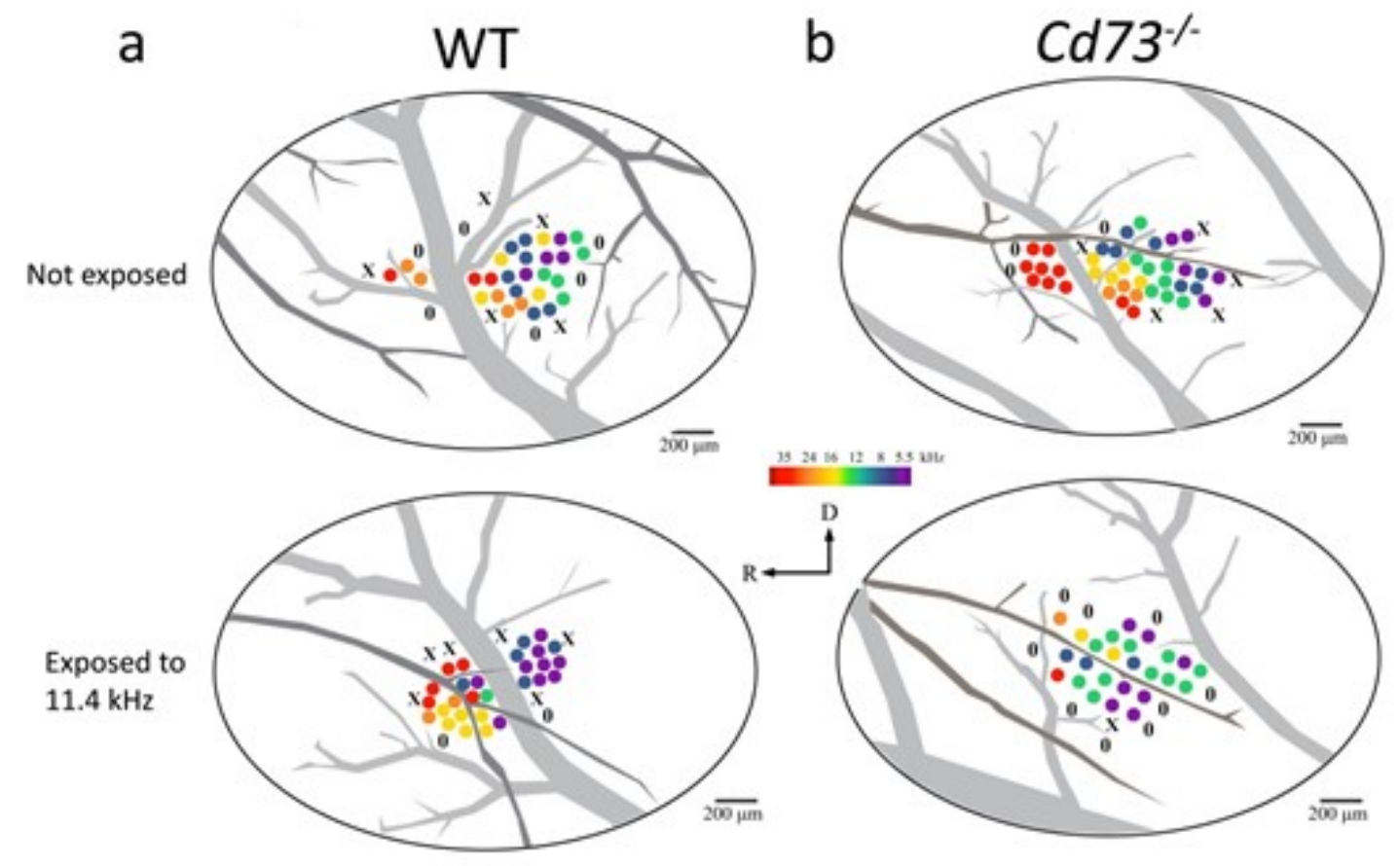

C
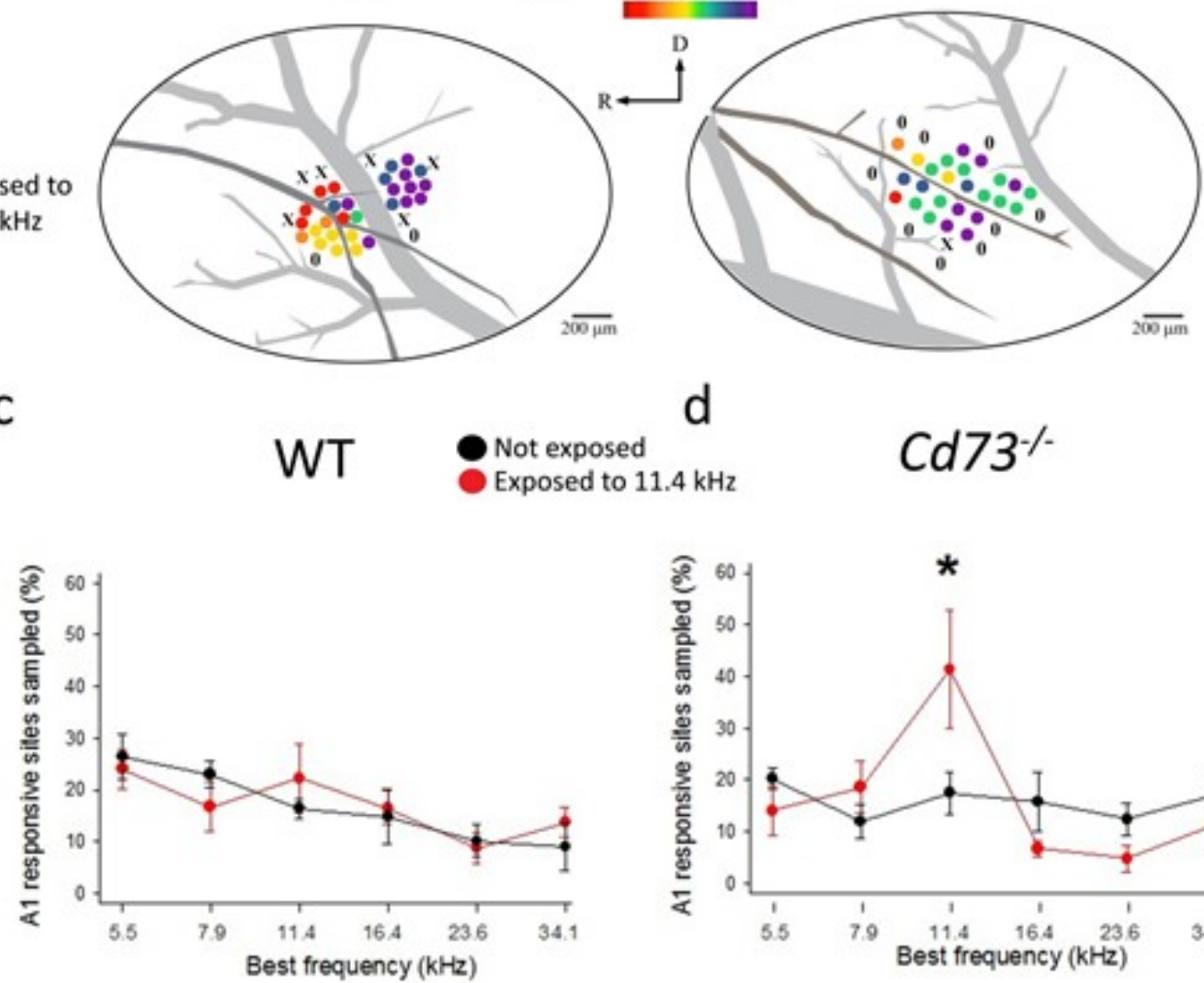

d

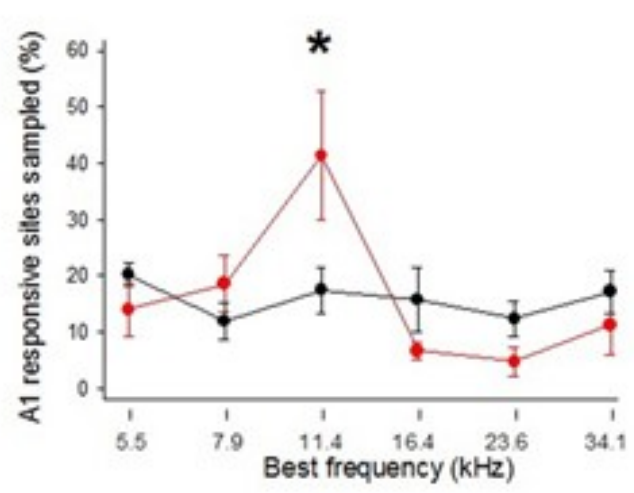

Figure 3-2. Cd73 deletion allows cortical map plasticity in mature mice to be induced by passive tone exposure.

Representative cortical maps of AI from a WT (a) and a $C D 73^{-/-}$(b) mouse exposed to no sound enrichment (top) and exposed to a repetitive $11.4 \mathrm{kHz}$ tone (bottom). The color of each circle represents the BF measured at that site. Null symbols represent unresponsive sites and "X"'s refer to sites located outside of AI based on response latency and poor tuning. Light gray depicts the rhinal vein and dark gray depicts the cerebral artery. R, rostral; D, dorsal. (c,d) The percentage of responsive recording sites in AI as a function of BFs in both WT (c) and $C d 73^{-/-}$(d) mice that are sound exposed to $11.4 \mathrm{kHz}$ and unexposed mice $* \mathrm{p}<0.05$. 


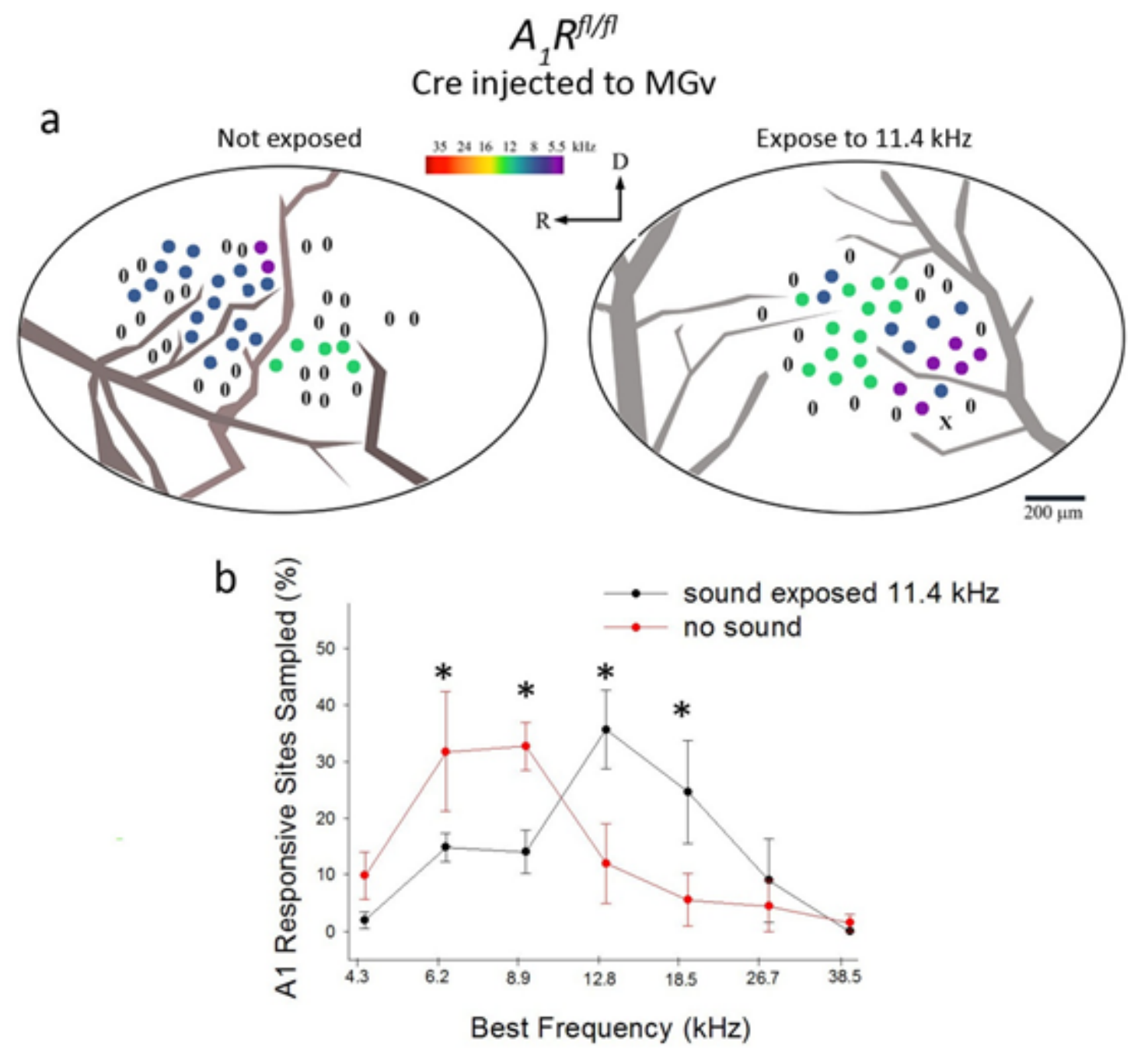

Figure 3-3. Disrupted tonotopic organization of cortical maps in mice with a conditional deletion of $A_{1} R$ in the MGv.

(a) Representative cortical maps from one $A_{1} R^{f l / f l}$ mouse injected with AAV-hSynapsinCre to the MGv exposed to no sound enrichment (left) and one mouse exposed to a repetitive $11.4 \mathrm{kHz}$ tone (right). The color of each circle represents the $\mathrm{BF}$ measured at that site. Null symbols represent unresponsive sites. Light gray depicts the rhinal vein and dark gray depicts the cerebral artery. R, rostral; D, dorsal. (b) The percentage of responsive recording sites in $\mathrm{AI}$ as a function of BFs from injected $A_{l} R^{f l f l}$ mice that are sound exposed to $11.4 \mathrm{kHz}$ and unexposed mice $* \mathrm{p}<0.05$. 


\subsection{Disordered Tonotopic Distribution in $A_{1} R^{f l / f l}$ Mice with a Conditional Deletion of $A_{1} R$ in the $A C x$ and Uninjected $A_{1} R^{f l / f l}$ Mice}

To further test that adenosine function is important at TC synapses and not corticocortical synapses, we injected AAV-hSynapsin-Cre into the ACx of $A_{1} R^{f l l f l}$ mice $(\mathrm{n}=7)$ and exposed them to two weeks of $11.4 \mathrm{kHz}$ (70dB SPL) sound enrichment. Deletion of $\mathrm{A}_{1} \mathrm{R}$ in the $\mathrm{ACx}$ should not affect presynaptic gating. $A_{1} R^{f l / f l}$ mice with a focal deletion of $\mathrm{A}_{1} \mathrm{R}$ in the $\mathrm{ACx}$ did not have normal $\mathrm{AI}$ tonotopic organization that ranged from low to high best frequencies in the caudal to rostral direction (Figure 3-4a).

To narrow down possible sources of these disordered tonotopic maps, I mapped $A_{1} R^{f l / f l}$ mice that were uninjected and did not undergo any sound exposure protocol $(\mathrm{n}=3)$. These mice also showed no tonotopic organization in their AI cortical map (Figure 3-4b). There is no significant difference between $A_{1} R^{f l l f l}$ mice with injections to the auditory cortex and the uninjected $A_{1} R^{f l / f l}$ mice $(\mathrm{p}<0.05)$. The only $A_{1} R^{f l / f l}$ mice that were significantly different from the rest had the Cre expressing virus injected to the MGv, exposed to sound. Without having validated the mouse construct or the virus, we can only speculate as to why the $A_{1} R^{f l f l l}$ mice do not have a normal tonotopic distribution. 


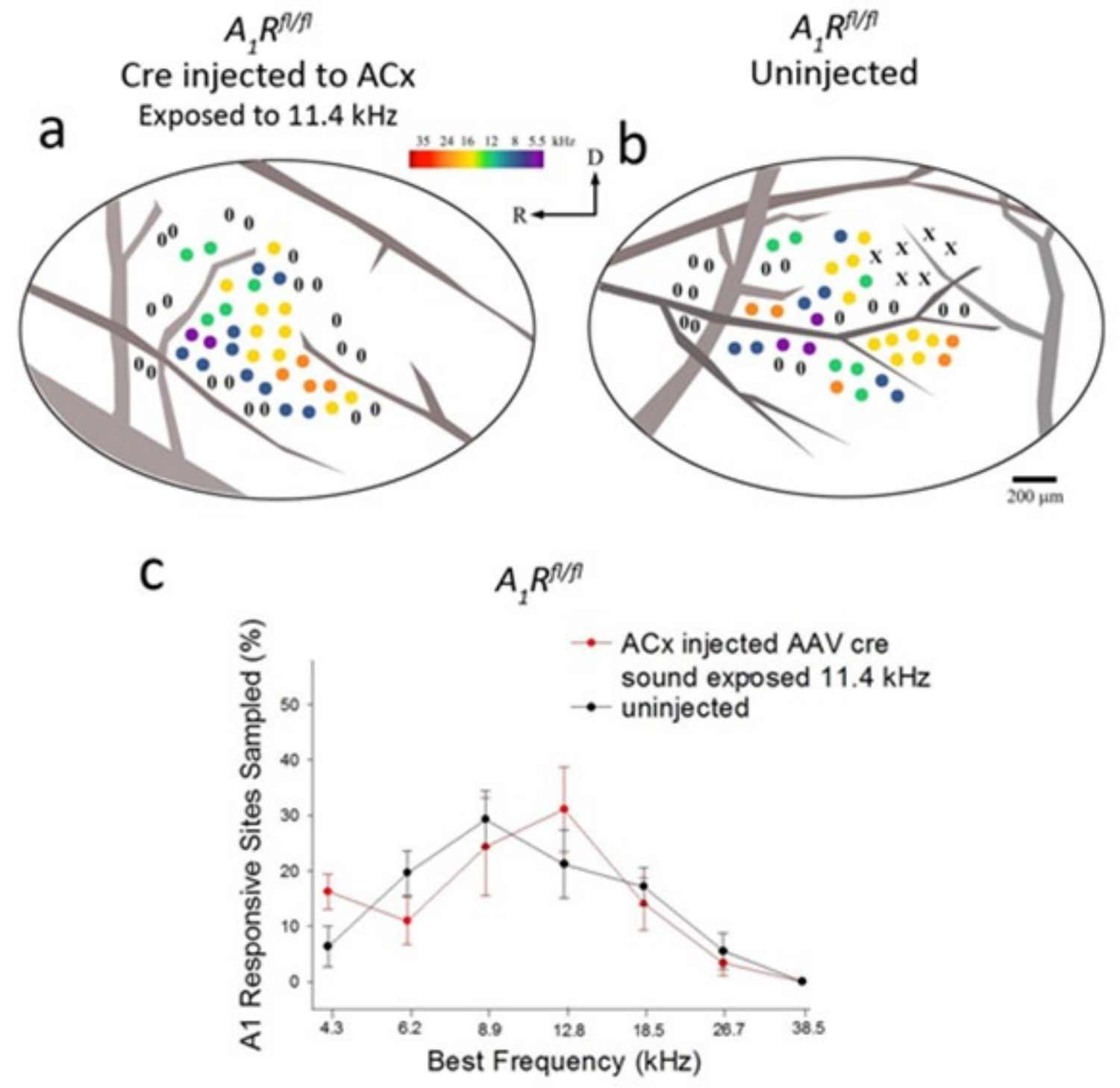

Figure 3-4. Disrupted tonotopic organization of cortical maps in mice with a conditional deletion of $A_{1} R$ in the $A C x$ and uninjected $A_{1} R^{f l / f l}$ mice.

(a) Representative cortical map from one $A_{1} R^{f l / f l}$ mouse injected with AAV-hSynapsinCre to the ACx exposed to $11.4 \mathrm{kHz}$ sound enrichment (b) Representative cortical map from $A_{1} R^{f l f l}$ mice that did not undergo any stereotaxic injections or sound exposure protocol. The color of each circle represents the BF measured at that site. Null symbols represent unresponsive sites. Light gray depicts the rhinal vein and dark gray depicts the cerebral artery. R, rostral; D, dorsal. (c) The percentage of responsive recording sites in $\mathrm{AI}$ as a function of BFs from ACx injected $A_{1} R^{f l f l}$ mice that are sound exposed to 11.4 $\mathrm{kHz}$ and uninjected $A_{1} R^{f l l f l}$ mice $* \mathrm{p}<0.05$. 


\section{CHAPTER 4. DISCUSSION}

Neural circuitry is highly influenced by sensory experience during early stages of development known as critical periods (Shatz and Katz, 1996). During these critical periods, primary sensory cortices are sensitive to stimuli and can easily undergo cortical plasticity, resulting in changes to topographic representations of the external environment. This allows animals to easily adapt to their environment early in life and create efficient connections as adults when neural circuits are more stable. The primary sensory cortices of adults are less likely to undergo plasticity, and must be specially modulated.

The AI cortical map is tonotopically organized, with neighboring regions having the greatest or best response to sounds of a similar frequency. Cortical plasticity of AI results in shifts of the tonotopic map, expanding or diminishing regions of BF. During the critical period in young mice, cortical plasticity is easy to induce solely by enriching the environment with a repetitive pure tone. In adults, passive sound exposure has no effect on tonotopic organization. In order for cortical plasticity to occur upon maturation, the tone must be behaviorally relevant to the environment of a mouse or paired with cholinergic inputs from the NB. Here we have shown that AI cortical plasticity may be the result of underlying synaptic plasticity at TC connections.

TC synapses can undergo synaptic plasticity during a critical period that extends for the first two weeks of life in mice (Crair and Malenka, 1995). The loss of synaptic plasticity in adults may be the result of the development of a presynaptic gating mechanism upon maturation of these synapses. The mechanisms to unmask postsynaptic LTP and LTD at TC synapses have been previously described (Blundon et al., 2011; Chun et al., 2013). Adenosine, a co-transmitter released at excitatory synapses, binds to presynaptic $A_{1} R$ receptors and negatively regulates glutamate release causing a gradual reduction in TC synaptic strength (Oswald et al., 2006; Dias et al., 2013). By inhibiting adenosine, glutamate release is sustained and the synaptic strength is robust enough to induce synaptic plasticity. Increased concentration of postsynaptic calcium through activation of group I mGluRs signals second messenger pathways to alter the number of glutamate receptors on the postsynaptic density.

We revealed that ungating long-term synaptic plasticity at TC projections to AI establishes critical period characteristics for inducing AI cortical plasticity. Because presynaptic adenosine at TC projections is produced in MGv neurons the main goal of our experiments was to reduce adenosine signaling in the MGv and test if this improves cortical map plasticity in adults. We first reduced adenosine function with the ubiquitous deletion of $\mathrm{A}_{1} \mathrm{R}$ and $\mathrm{Cd} 73$ in adult mice that underwent passive exposure to pure tones of a single frequency. After cortical mapping, we observed shifts in BFs towards that frequency, which was not evident in WT controls. By removing the presynaptic adenosine gate, we have shown that adult mice can revert back to the critical period and passively undergo cortical plasticity without cholinergic or behavior modification. 


\subsection{Cortical Plasticity in $A_{1} R$ and $C d 73$ General Knockouts}

$A_{1} R^{-/-}$mice underwent cortical plasticity with expansion of AI towards their specific enrichment frequency, $7 \mathrm{kHz}$. This is the first evidence that supports adenosinedependent presynaptic gating as the cellular mechanism of cortical plasticity in adults. Without the ability of adenosine to $\mathrm{A}_{1} \mathrm{R}$, adult mice revert back critical period plasticity undergo shifts in their BF solely through passive tone exposure.

Interestingly, the cortical maps of $A_{1} R^{-/-}$mice showed a significant expansion of the area that responded best to not only $7.9 \mathrm{kHz}$ but also $5.5 \mathrm{kHz}$. It is possible that expansion of the $5.5 \mathrm{kHz}$ AI region is the result of the representation of frequencies in groups of two, or bins. The BF is determined by the frequency that generates the most spike response at a specific region, but is represented by the number of tone-evoked extracellular responses recorded for two frequencies. The number of responses are totaled, grouped, and considered to be one BF even though the data is collected from two frequencies. The $A_{1} R^{-/-}$mice were passively exposed to a $7 \mathrm{kHz}$ tone but they were never played a $7 \mathrm{kHz}$ tone during mapping. Data was collected using $6.4 \mathrm{kHz}$ and $7.9 \mathrm{kHz}$ tones. Although they are closest to $7 \mathrm{kHz}$ they were grouped separately. The $5.5 \mathrm{kHz}$ frequency is representative of a bin that also included the $6.4 \mathrm{kHz}$ tone. This may explain the rise in the area of AI that responds to both groups because they are the closest representation of $7 \mathrm{kHz}$.

Unlike the $A_{1} R^{-/-}$mice, the $C d 73^{-/-}$mice were both exposed and mapped using an $11.4 \mathrm{kHz}$ tone. We saw a specific increase in the expansion of AI with best responses to that frequency alone. Although the $\mathrm{A}_{1} \mathrm{R}$ is required for the mechanism of presynaptic gating, testing $C d 73^{--}$mice further supports our findings by demonstrating that there must be adenosine co-released at the TC synapse for gating to occur. Indeed, pharmacological or genetic blockade of CD73 was sufficient to release gating for both TC LTP and LTD in the auditory cortex (Blundon et al., 2011; Chun et al., 2013), Cd73 ${ }^{-1}$ mice were not used in LTP/LTD studies, and therefore should be tested for plasticity at TC synapses in brain slices.

We did not attempt to perform in vivo experiments with the application of $A_{1} R$ and $\mathrm{Cd} 73$ inhibitors. In the presence of 8-cyclopentyl-1,3-dipropylxanthine (DPCPX), an $\mathrm{A}_{1} \mathrm{R}$ selective antagonist, synaptic plasticity was inducible in TC slices taken from adult WT mice (Blundon et al., 2011; Chun et al., 2013). Similar results were seen using $\alpha, \beta-$ methylene-ADP, which inhibits Cd73 (Blundon et al., 2011; Chun et al., 2013). We could use this approach for in vivo studies by injecting WT mice with either of these two inhibitors during passive sound exposure followed by cortical mapping to determine if they underwent cortical plasticity. This method would provide systemic inhibition of adenosine machinery, which would complement our data from $\mathrm{A}_{1} \mathrm{R}$ and $\mathrm{Cd} 73$ knockout mice. 


\subsection{Cortical Plasticity in the $A_{1} R$ Conditional Knockout}

Although we saw cortical plasticity in the $A_{1} R^{-/-}$and $C d 73^{-/-}$mice, these are general knockouts and do not specifically demonstrate that it is the role of adenosine in the $\mathrm{MGv}$ that is responsible for gating plasticity. It is still questionable whether deletion of adenosine function at corticocortical synapses in the $A_{1} R^{-/-}$and $C d 73^{-/-}$mice is responsible for cortical plasticity. We therefore attempted to create conditional knockouts of $\mathrm{A}_{1} \mathrm{R}$ in the MGv with the Cre-LoxP system using $A_{1} R^{f l f l}$ mice (Scammell et al., 2003). At the time there was no available mouse line that expressed thalamic specific Cre so instead we turned to viral deletion of $\mathrm{A}_{1}$ Rs using an AAV-Synapsin-Cre-GFP vector. By injecting the virus into the $\mathrm{MGv}$ or $\mathrm{ACx}$, we could show that deletion specifically of thalamic $A_{1}$ Rs is necessary for cortical plasticity, not deletion of $A_{1}$ Rs at intracortical connections or any other projections that are affected in general knockouts.

While the $A_{1} R^{f l f l}$ mice injected with hSynapsin-Cre to the MGv seemed to show cortical plasticity towards middle frequencies close to the passive $11.4 \mathrm{kHz}$ tone, none of our control mice, injected and uninjected, had a normal distribution of BFs across AI. Regardless of the site of the injection or the sound exposure protocol, these $A_{l} R^{f l f l}$ mice had similar patterns of disorganization. Moreover, $A_{1} R^{f l f l}$ mice that had no virus injections and did not undergo a sound exposure protocol also have disorganized cortical maps. It is promising that the only maps that were significantly different came from sound exposed $A_{1} R^{f l f l l}$ mice with Cre expression in the MGv. There was no significant difference in cortical maps from mice left with the MGv intact. This may support the $\mathrm{MGv}$ and TC connections as the source of cortical plasticity.

Unfortunately, we did not validate the construct of these mice beforehand so we can only speculate as to why these mice have disordered tonotopy. After reviewing the construct for production of the $A_{1} R^{f l f l}$ mice, we found that there may be disruption of $\mathrm{A}_{1} \mathrm{R}$ transcription due to the presence of a Neomycin (Neo) cassette just after exon 2 of the $\mathrm{A}_{1} \mathrm{R}$ gene, Adora. The placement of this Neo cassette could potentially disrupt expression or function of the receptor, creating abnormal development of the tonotopic map at thalamocortical synapses. The exon 2 and Neo cassette are separately floxed to be removed by the presence of Cre but adult $A_{1} R^{f l f l}$ mice without Cre may have abnormal expression of Adoral.

There are multiple ways to test whether the Neo cassette is modifying $A_{1} R$ expression on either the mRNA or protein level. The promoter of the Neo cassette could be influencing the mRNA stability or splicing of Adoral. We have recently measured $\mathrm{A}_{1} \mathrm{R}$ mRNA levels in the MGv by qPCR using primer sets for exon 1 (5'TGTGCCCGGAAATGTACTGG-3' and 5'-TCTGTGGCCCAATGTTGATAAG-3') and saw two-fold up regulation of $\mathrm{A}_{1} \mathrm{R}$ in $A_{1} R^{\text {fllfl }}$ mice compared to WT. This was confirmed using primer sets for exon 2 (5'-GGCCACAGACCTACTTCCAC-3' and 5' CCACAGCAATAGCAAGCAGAG-3') which also show an increase in $\mathrm{A}_{1} \mathrm{R}$.

It is possible that even if the mRNA levels of $A_{1} R$ are increased, due to splice alterations the Neo cassette may be included in the mRNA transcript. This could 
potentially create unstable mRNA or a nonfunctional protein. The Neo cassette is necessary for positive selection from the electroporation of the targeting vector. Because it is floxed, Cre could have been used to remove the Neo cassette while maintaining the integrity of exon 2. Another alternative would be to use the FLP-FRT system for sitedirected recombination and removal of the Neo cassette without affecting exon 2.

Due to the disrupted tonotopic maps seen in the $A_{1} R^{f l / f l}$ mice, we did not validate deletion of the floxed $\mathrm{A}_{1} \mathrm{R}$ by the hSynapsin-Cre-GFP virus. In order to include the cortical maps from injected mice in our data, we need to verify that the MGv was properly targeted and transduced with virus. To measure levels of $\mathrm{A}_{1} \mathrm{R}$ in injected mice, we can perform either qPCR or Western blot on thalamic tissue after cortical mapping. Brains could also be removed, sliced, and imaged for GFP detection at the site of injection. The MGv is an extremely small nucleus of the thalamus and therefore it is easy to partially inject the correct region or miss it completely; it is also prone to physical damage by the cannula because of its size. By injecting too much virus too quickly, thalamic projections are easily damaged. If part of the $\mathrm{MGv}$ is not infected with virus or thalamic cells are damaged, this could skew the tonotopic organization of cortical maps. Therefore, targeting of the MGv, injection volume, and injection speed must be carefully optimized. Furthermore, we did not do any experiments that controlled for the virus by injecting another virus with an hSynapsin promoter that does not express Cre.

Many additional experiments are necessary to determine possible reasons for abnormal BF distribution in the $A_{1} R^{f l / f l}$ mice. Had we validated our construct before performing cortical mapping experiments we could have potentially foreseen and addressed these issues by taking another approach and a new create a conditional $A_{1} R$ knockout using more appropriate methods.

\subsection{New Approaches to Create a Conditional Knockout/Knockdown Mouse}

Although the construct we used for the $A_{1} R^{f l f l}$ mouse was not useful for creating a conditional knockout of the adenosine receptor at thalamocortical synapses, there are many other approaches using different techniques. The first would be to create a new construct with a floxed $\mathrm{A}_{1} \mathrm{R}$ that has no disrupting Neo cassette. This technique could also be used to create a mouse line with floxed Cd73. By removing selectors from the construct, such as a Neo cassette, these mice should not have any disruption in Adoral or $C d 73$ and express normal proteins. Recently, a mouse line became available for purchase (The Jackson Laboratory), with inducible Cre under a Gbx2 promoter that expressed specifically in excitatory and inhibitory thalamic neurons (Chen et al., 2009; Normand et al., 2013). Paring a new $A_{1} R^{f l / f l}$ or $C d 73^{f l / f l}$ mouse with a Gbx2-Cre-ER mouse should create a conditional knockout of the adenosine receptor or adenosine-producing enzyme specifically in the thalamus. These mice should undergo tamoxifen injections around P30 to induce the expression of Cre in mature animals. Although this approach does not allow for conditional deletion of adenosine machinery in the ACx to rule out intracortical connections, it provides more accurate targeting of the thalamus compared to stereotaxic viral injections. 
Knockdown of Adoral or Cd73 using short hairpin RNA (shRNA) expressing lentivirus vectors in WT mice is a second technical approach to remove adenosine machinery from thalamic cells. shRNAs enter the cell and integrate into DNA through viral infection. They then are cleaved and exported into the cytoplasm for further processing before it binds to the RNA-induced silencing complex (RISC) to create longterm knockdown of a targeted gene by binding to mRNA and preventing translation (Moore et al., 2010). Lentivirus vectors expressing various shRNAs targeting a selected gene are available for purchase, expressing the anti-sense sequence of the intended gene under a ubiquitous promoter (Applied Biological Materials). Although this technique is suitable for creating a conditional knockdown, there are many potential concerns because it is hard to target the MGv and each mouse must be validated using qPCR for a significant reduction in $\mathrm{A}_{1} \mathrm{R}$ or $\mathrm{CD} 73$. There is also the potential for off-target effects that must be taken into consideration, in which the shRNA targets additional transcripts. Other technical concerns include virus toxicity, physical damage from the cannula, and targeting the entire MGv.

\subsection{Future Directions}

\subsubsection{Development of thalamocortical gating of cortical plasticity}

There must be age-related changes occurring in the circuitry that regulates cortical plasticity during development and the offset of the critical period. It is unknown if the gating circuitry is present but nonfunctional during the critical period or whether it develops with the maturation of circuitry. Gating may be present and unregulated during the critical period. The critical period may coincide with heightened activity of cholinergic inputs that increase the release of the gate allowing cortical plasticity to occur passively (Hohmann and Berger-Sweeney, 1998).

It is also possible that the gating mechanism is not present during the critical period but develops at the offset of the critical period. This may be due to an increase in the function of adenosine through increased $\mathrm{A}_{1} \mathrm{R}$ receptors or adenosine production by Cd73 (Blundon and Zakharenko, 2013). Levels of both $A_{1} R$ and $C d 73$ can be measured by qPCR from the thalamic tissue of WT mice during the critical period and during adulthood. If the offset of the critical period is caused by changes in adenosine, adult mice should have higher levels of $A_{1} R$ and/or Cd73. Levels of adenosine can be directly measured from thalamic tissue by high-performance liquid chromatography (HPLC). Although an increase in the levels of adenosine in mature animals does not mean that there is increased co-release of adenosine at mature TC synapses, it does provide insight into the development of the presynaptic gating mechansim. Changes to adenosine and cholinergic inputs may both be the source for the development of thalamocortical gating that regulates cortical plasticity. 


\subsubsection{Lasting changes to the AI cortical map}

In our experiments, mice underwent the sound or no sound exposure protocol for approximately two weeks followed by almost immediate mapping to determine if cortical plasticity had occurred. Although our data shows that in this timeframe both $A_{1} R^{-/-}$and $C d 73^{-/-}$mice undergo shifts in their tonotopic maps towards passive tone frequency, there is little indication about how quickly these cortical changes occur and how long they last. Furthermore, because all of our mice were under three months of age, we do not know whether this plasticity can be induced further into adulthood.

When cortical plasticity is induced in AI of rodents through behavioral training, the speed at which map expansion occurs and how long it lasts is thought to be dependent on the difficulty of the training task (Rutkowski and Weinberger, 2005; Reed et al., 2011). The harder the task, the greater the area of plasticity and the longer it will take for tonotopic reorganization to occur. Although our mice are undergoing cortical plasticity passively, this data gives reason to believe that the period of tone exposure may affect the degree of plasticity and the rate at which the tonotopic maps will eventually renormalize.

To test this, conditional knockout mice missing $\mathrm{A}_{1} \mathrm{R}$ or $\mathrm{Cd} 73$ can undergo passive exposure for different periods of time before mapping to determine not only how quickly cortical plasticity occurs but also the degree of map expansion. For example, cortical plasticity may occur after five days, but there may be greater expansion in cortical map after two weeks. It has been previously shown that cortical map changes are often transient and can revert back to normal over time (Reed et al., 2011). Again, this may depend upon the amount of time spent in the sound enrichment chambers. Mice can be removed from the chambers and reenter a normal acoustic environment for different periods of time before they are mapped to determine whether reorganization occurs and if so, how long it takes to normalize.

The age at which we tested our mice for cortical plasticity has been limited by using the C57BL/6 inbred strain. All of the mice we have used for our experiments are on a C57BL/6 background, and therefore are subject to cochlear degeneration (Willott, 1986). Hearing loss can begin in C57BL/6 mice as early as the second month of life beginning with loss of high frequency detection and complete deafness by six to twelve months (Ison et al., 2007). High frequency hearing loss often results in an expansion of the representation of low frequencies in the AI cortical map (Willott et al., 1993). This has made it difficult to determine whether mechanisms of cortical plasticity differ with increasing age.

To address this, we would have to use a different inbred mouse strain that does not develop hearing loss, such as CBA mice that have no signs of hearing loss within the first year of life (Willott, 1986). $A_{1} R^{-/-}$or $C d 73^{-/-}$mice can be backcrossed onto a CBA background to generate general knockouts. To create conditional knockouts, WT CBA mice can be injected with shRNA vectors previously mentioned. Without concerns of hearing loss, knockout mice on the CBA background can undergo passive tone exposure 
and mapped at increasing ages to determine if the mechanisms of cortical plasticity differ at older ages.

\subsubsection{Improved learning with cortical map plasticity}

Cortical map changes are associated with the degree to which a rodent can learn an auditory behavioral task. The more motivated an animal is to learn a difficult task, the greater expansion of AI towards the behaviorally associated frequency (Rutkowski and Weinberger, 2005). Reed et al. (2011) showed that cortical map plasticity in rats improves learning in auditory discrimination tasks. Given that $A_{1} R^{-/-}$and $C d 73^{-/-}$adult mice can easily undergo cortical plasticity compared to their WT counterparts, this may suggest that they are better learners in a behavioral context. Furthermore, the speed at which they learn behavioral tasks may improve if they undergo passive exposure to the tone frequency beforehand. Mice can be trained with a go/no-go auditory discrimination task to determine how well they perform as a measure of learning. Mice can undergo passive tone exposure before they undergo training for the behavioral task to determine whether cortical map changes beforehand improve learning.

\subsubsection{Presynaptic gating and acetylcholine modulation}

Cholinergic projections have been shown to modulate the strength of synaptic plasticity at excitatory synapses (Abe et al., 1994; Maeda et al., 1994; McCutchen et al., 2010). Previous studies have demonstrated that ACh release from the NB modulates AI cortical plasticity by binding to $\mathrm{M}_{1}$ muscarinic receptors (Kilgard and Merzenich, 1998; Froemke et al., 2007), but the mechanism of how ACh modulates plasticity is still disputed. Previous research has shown that ACh from the NB sustains TC synaptic transmission (Metherate and Ashe, 1993). Our hypothesis that cortical plasticity in adults is a result from release of a presynaptic gate at TC synapses provides a mechanism for the role of ACh in cortical plasticity. At TC synapses, ACh inhibits the function of adenosine at the presynaptic cell by possibly inhibiting adenosine release or blocking $\mathrm{A}_{1}$ Rs.

Thalamic inputs into the cortex are weak and only account for $15-20 \%$ of L4 synapses (Buonomano and Merzenich, 1998; Bruno and Sakmann, 2006). It has been suggested that ACh affects cortical plasticity by modulating predominantly excitatory and inhibitory intracortical cells rather than thalamic inputs (Froemke et al., 2007; Froemke et al., 2013). ACh has been shown to effect AI cortical plasticity in adults when environmental stimuli become behaviorally relevant. By passively inducing cortical plasticity in general knockouts of $\mathrm{A}_{1} \mathrm{R}$ and $\mathrm{Cd} 73$ there still may be a question as to whether ACh is influencing cortical plasticity at TC synapses or through another mechanism upon intracortical connections.

To test this in vivo, ACh modulation should be blocked in mice without thalamic $A_{1} R$ or $C d 73$. This can be done through administration of cholinergic inhibitors or 
physical ablation of projections from the NB. One technical approach includes cortical application of the muscarinic competitive antagonist, atropine, which has been shown to block cortical plasticity induced by NB stimulation in vivo (Froemke et al., 2007). Even when blocking cholinergic projections from the $\mathrm{NB}$, knockout mice missing thalamic $\mathrm{A}_{1} \mathrm{R}$ or $\mathrm{Cd} 73$ should still undergo cortical plasticity through passive tone exposure. Another approach to remove $\mathrm{ACh}$ from acting upon the $\mathrm{ACx}$ is through surgical ablation of the NB to sever cholinergic projections in $\mathrm{A}_{1} \mathrm{R}$ or $\mathrm{Cd} 73$ mice. Regardless of $\mathrm{ACh}$ input, these mice should still undergo cortical plasticity by sound enrichment because $\mathrm{ACh}$ modulation is upstream of adenosine. These experiments can further support our hypothesis by showing that cortical plasticity is occurring through plasticity TC synapses through gating of adenosine. Regardless of cholinergic inputs onto AI, cortical plasticity can still occur through passive sound exposure by removal of the presynaptic gating mechanism.

\subsubsection{Mechanisms of cortical plasticity for other primary sensory cortices}

Similar to AI, all primary sensory cortices undergo early sensitivity to sensory stimuli during an early critical period that stabilizes into adulthood. The NB projects to all primary sensory cortices and plays an important role in sensory learning. For example, cholinergic projections to the primary motor cortex are necessary for cortical plasticity and learning of new motor skills (Conner et al., 2003; Reed et al., 2011). Consequently, we can test whether adenosine related presynaptic gating at TC synapses affects cortical plasticity in other primary sensory regions.

One possible approach would be to target different regions of the thalamus projecting to other primary cortices with shRNA lentivirus vectors targeting $A_{1} R$ or Cd73. For example, to target the primary visual cortex (VI), adenosine machinery can be inhibited in the lateral geniculate nucleus (LGN) of the thalamus. These mice can then be tested for cortical plasticity by depriving visual input into one eye. In adults with normal development of VI, there is an equal thalamic input to VI from both eyes and monocular deprivation has no effect on this distribution. During the critical period, thalamic projections from the deprived eye recede and the majority of thalamic projections to VI are from the eye receiving visual input. If TC presynaptic gating regulates cortical map plasticity at VI, the removal of adenosine should cause thalamic input from the nondeprived eye to expand across VI.

\subsection{Broader Implications}

Cortical map plasticity is studied to better understand perceptual learning and memory about the sensory environment. Modifications in the complex circuitry of primary sensory cortices are thought to result from behavioral adaptations due to changes in the external environment. By understanding the mechanisms of cortical plasticity in adults, it can be used as a tool to reopen the critical period for enhanced learning or to treat sensory disorders. 


\subsubsection{Cortical plasticity to improve learning}

In the first few years of life, humans undergo enormous growth both physically and intellectually. This is the time in which we experience an incredibly rapid development during numerous critical periods, ranging from the development of motor skills to speaking and understanding language. These are sensitive periods in which babies and children can easily learn and develop specific skills that are not so easily learned later in life. Critical periods in humans often span a period of months in which children become accustomed to their environment, whether it is the people, language, or places. In this time, our brains are highly plastic; new pathways are easily developed and strengthened before they mature and become consolidated.

Development of language is one of the most prominent, highly studied critical periods. In the womb, full-term babies can detect sounds similar to adults (Winkler et al., 2003). Language acquisition begins at three months and by six months humans have a advanced understanding of the phonetics of their native language and begin to lose the ability to learn phonetic sounds from other languages (Hensch, 2004). After the first year, it is difficult for babies to hear and produce sounds from their nonnative language (Hensch, 2004). For example, it is difficult for native Japanese speakers to distinguish between "l" and "r" pronunciations (Hensch, 2004).

It has been suggested that by reopening critical periods, adults can learn skills as naturally as children (Hensch, 2004). This includes the auditory critical period for developing better detection of the features of sounds. As we have shown, inhibiting the function of adenosine in thalamic projections to AI, we can extend the auditory critical period in mature mice. This therefore might serve as a potential target for reopening the critical period in humans and can be used for skills such as learning a new language. This may also be useful for musicians to develop perfect pitch, which is often learned during the auditory critical period. It is nearly impossible for adults to acquire perfect pitch after this period, but by reopening the critical period adults can be trained to discriminate between tones (Gervain et al., 2013; Hensch, 2014).

\subsubsection{Cortical plasticity to treat disease}

Many psychiatric and neuronal disorders are associated with abnormal sensory perception that can often result in severe, painful side effects. For example, peripheral nerve damage can lead to changes in sensor perception that cause cortical map reorganization. Patients who suffer from tinnitus have cochlear damage that causes them to perceive a constant ringing in their ears even when no actual sound is present (Eggermont and Roberts, 2004). This can be an irritating and often debilitating phenomenon that results in reorganization to the AI cortical map towards the frequency of the ringing. Similarly, amputees can perceive pain coming from their missing limb, known as phantom limb pain, which can generate cortical plasticity changes to the somatosensory cortex. 
Understanding the mechanisms of cortical plasticity could help improve treat of these diseases by reversing changes that occur to the cortical map (Kilgard, 2013).

Current studies are harnessing ACh modulation to induce AI cortical map reorganization as a treatment for tinnitus. In humans, stimulation of the vagus nerve has been shown to have similar effects on AI cortical plasticity as NB stimulation in animals (Engineer et al., 2011). ACh release through vagus nerve stimulation can be paired with a tone of a frequency to create cortical map reorganization. The associated tone should have a frequency different from that experienced during the tinnitus. Therefore, the map can reorganize and shift away from the expanded frequency.

This type of treatment has been shown to work using animal models of tinnitus (Engineer et al., 2011) and is currently being used in a clinical trial for tinnitus patients (Kilgard, 2013). Vagus nerve stimulation may function by activating cholinergic inputs onto AI and releasing the presynaptic gate for cortical plasticity. Inducing cortical plasticity using adenosine inhibitors should have a similar but less controlled effect on tonotopic map reorganization to treat sensory disorders. ACh affects cortical plasticity in all sensory cortices, making this a potential tool to treat other sensory disorders through cortical plasticity. 


\section{CHAPTER 5. CONCLUSION}

Our results suggest that adenosine-dependent presynaptic gating at TC synapses is the cellular mechanism of cortical plasticity at the mature AI. By removing the gating through genetic deletion of $\mathrm{A}_{1} \mathrm{R}$ or $\mathrm{Cd} 73$, mature mice are able to undergo cortical plasticity through passive tone exposure. Because this form of cortical plasticity has previously only been demonstrated in young mice during the critical period, we propose that removing adenosine machinery at TC synapses extends the critical period in adults. 


\section{LIST OF REFERENCES}

Abe K, Nakata A, Mizutani A, Saito H (1994) Facilitatory but nonessential role of the muscarinic cholinergic system in the generation of long-term potentiation of population spies in the dentate gyrus in vivo. Neuropharmacology 33:847-852.

Barnes SJ, Finnerty GT (2010) Sensory experience and cortical rewiring. The Neuroscientist 16(2):186-198.

Bieszczad KM, Weinberger NM (2012) Extinction reveals that primary sensory cortex predicts reinforcement outcome. Eur J Neurosci 35:598-613.

Bliss TVP, Collingridge GL (1993) A synaptic model of memory: long-term potentiation in the hippocampus. Nature 361:31-39.

Blundon JA, IT Bayazitov, Zakharenko SS (2011) Presynaptic gating of postsynaptically expressed plasticity at mature thalamocortical synapses. J Neurosci 31(44):1601216025.

Blundon JA, Zakharenko SS (2013) Presynaptic gating of postsynaptic synaptic plasticity: a plasticity filter in the adult auditory cortex. The Neuroscientist 19(5):465-478.

Bruno RM, Sakmann B (2006) Cortex is driven by weak by synchronously active thalamocortical synapses. Science 312:1622-1627.

Buonomano DV, Merzenich MM (1998) Cortical plasticity: from synapses to maps. Annu Rev Neurosci 21:149-186.

Carcea I, Froemke RC (2013) Cortical plasticity, excitatory-inhibitory balance, and sensory perception. Progress in Brain Res 207:65-89.

Chen L, Guo Q, Li JYH (2009) Transcription factor Gbx2 acts cell-nonautonomously to regulate the formation of lineage-restriction boundaries of the thalamus. Development 136:1317-1326.

Chun S, Bayazitov IT, Blundon JA, Zakharenko SS (2013) Thalamocortical long-term potentiation becomes gated after the early critical period in the auditory cortex. J Neurosci 33(17):7345-7357.

Conner JM, Culberson A, Packowski C, Chiba AA, Tuszynski MH (2003) Lesions of the basal forebrain cholinergic system impair task acquisition and abolish cortical plasticity associated with motor skill learning. Neuron 38:819-829. 
Crair MC, Malenka RC (1995) A critical period for long-term potentiation at thalamocortical synapses. Nature 375:325-328.

de Villers-Sidani E, Chang EF, Bao S, Merzenich MM (2007) Critical period window for spectral tuning defined in the primary auditory cortex (AI) in the rat. J Neurosci 27(1)180-189.

Dias RB, Rombo DM, Ribeiro JA, Henley JM, Sebastião AM (2013) Adenosine: setting the stage for plasticity. Trends in Neurosci 36(4):248-257.

Eggermont JJ, Roberts LE (2004) The neuroscience of tinnitus. Trends Neurosci 27:676682.

Engineer ND, Riley JR, Seale JD, Vrana WA, Shetake JA, Sudanagunta SP, Borland MS, Kilgard MP (2011) Reversing pathological neural activity using targeted plasticity. Nature 470:101-104.

Froemke RC, Merzenich MM, Schreiner CE (2007) A synaptic memory trace for cortical receptive field plasticity. Nature 450(15):425-429.

Froemke RC, Jones BJ (2011) Development of auditory cortical synaptic receptive fields. Neurosci Biobehav Rev 35(10):2105-2113.

Geissler DB and G Ehret (2004) Auditory perception vs. recognition: representation of complex communication sounds in the mouse auditory cortical fields. Eur J Neurosci 19:1027-1040.

Gervain J, Vines BW, Chen LM, Seo RJ, Hensch TK, Werker JF, and Young AH (2013) Valproate reopens critical-period learning of absolute pitch. Front Syst Neruosci 7(102):1-11.

Guo W, Chamber AR, Darrow KN, Hancock KE, Shinn-Cunningham BG, Polley DB (2012) Robustness of cortical topography across fields, laminae, anesthetic states, and neurophysiological signal types. J Neurosci 32(27):9159-9172.

Hackett TA, Barkat TR, O’Brien BMJ, Hensch TK, Polley DB (2011) Linking topography to tonotopy in the mouse auditory thalamocortical circuit. J Neurosci 31(8):2983-2995.

Hensch TK (2004) Critical Period Regulation. Annu Rev Neurosci 27:549-579.

Hensch TK (2014) Want perfect pitch? You may be able to pop a pill for that. NPR. 04 Jan 2014.

Hohmann CF, Berger-Sweeney J (1998) Cholinergic regulation of cortical development and plasticity. New twists to an old story. Persepct Dev Neruobiol 5:401-425. 
Hu B (2003) Functional organization of lemniscal and nonlemniscal auditory thalamus. Exp Brain Res 153:543-549.

Ison JR, Allen PD, O’Neill WE (2007) Age-related hearing loss in C57BL/6J mice has both frequency-specific and non-frequency-specific components that produce a hyperacusis-like exaggeration of the acoustic startle reflex. J Assoc Res Otolaryngol 8(4):539-550.

Johansson B, Halldner L, Dunwiddie TV, Masino SA, Poelchen W, Giménez-Llort L, Escorihuela RM, Fernández-Teruel A, Wiesenfeld-Hallin Z, Xu XJ, Hârdemark A, Betscholtz C, Herlenius E, Fredholm BB (2001) Hyperalgesia, anxiety, and decreased hypoxic neuroprotection in mice lacking the adenosine A1 receptor. Proc Natl Acad Sci U S A 98:9407-9412.

Kaas JH (1991) Plasticity of sensory and motor maps in adult animals. Annu Rev Neurosci 14:137-167.

Katz LC, Shatz CJ (1996) Synaptic activity and the construction of cortical circuits. Science 24(5290):1133-1138.

Keuroghlian AS, Knudsen EI (2007) Adaptive auditory plasticity in developing and adult animals. Prog Neurobiol 82:109-121.

Kilgard MP, Merzenich MM (1998) Cortical map reorganization enabled by nucleus basalis activity. Science 279:1714-1718.

Kilgard MP (2005) Cortical map reorganization with cholinergic modulation. Neuron 48(4):529-530.

Kulesskaya N, Voikar V, Peltola M, Yegutkin GG, Salmi M, Jalkanen S, Rauvala H (2013) CD73 Is a Major Regulator of Adenosinergic Signaling in Mouse Brain. PLoS ONE 8(6): e66896. doi:10.1371/journal.pone.0066896

Ma X, Suga N (2009) Specific and nonspecific plasticity of the primary auditory cortex elicited by thalamic auditory neurons. J Neurosci 29(15):4888-4896.

Maeda T, Kaneko S, Satoh M (1994) Roles of endogenous cholinergic neurons in the induction of long-term potentiation at hippocampal mossy fiber synapses. Neurosci Res 20:71-78.

Malenka RC, Bear MF (2004) LTP and LTD: an embarrassment of riches. Neuron 44:521.

Merzenich MM, Sameshima K (1993) Cortical plasticity and memory. Curr Opin Neurobiol 3:187-196. 
Metherate R, Ashe JH (1993) Nucleus basalis stimulation facilitates thalamocortical synaptic transmission in the rat auditory cortex. Synapse 14:132-43.

McCutchen E, Scheiderer CL, Dobrunz LE, McMahon LL (2006) Coexistence of muscarinic long-term depression with electrically induced long-term potentiation and depression at CA3-CA1 synapses. J Neurophysiol 96:3114-3121.

Moore CB, Guthrie EH, Tze-Han Huang M, Taxman DJ (2010) Short hairpin RNA (shRNA): design, delivery, and assessment of gene knockdown. Methods Mol Biol 629:141-158.

Normand EA, Crandall SR, Thorn CA, Murphy EM, Voelcker B, Browning C, Machan JT, Moore CI, Connors BW, Zervas M (2013) Temporal and mosaic Tsc1 deletion in the developing thalamus disrupts thalamocortical circuitry, neural function, and behavior. Neuron 78(5):895-909.

Oswald AM, Schiff ML, Reyes AD (2006) Synaptic mechanisms underlying auditory processing. Curr Opin Neurobiol 16:371-376.

Pettit DL, Wang SS, Gee KR, Augustine GJ (1997) Chemical two-photon uncaging: a novel approach to mapping glutamate receptors. Neuron 19(3):465-471.

Polley DB, Steinberg EE, Merzenich MM (2006) Perceptual learning directs auditory cortical map reorganization through top-down influences. J Neurosci 26:49704982.

Rauschecker JP (1999) Auditory cortical plasticity: a comparison with other sensory system. Trends Neurosci 22:74-80.

Reed A, Riley J, Carraway R, Carrasco A, Perez C, Jakkamsetti V, Kilgard MP (2011) Cortical map plasticity improves learning but is not necessary for improved performance. Neuron 70:121-131.

Rutkowski RG, Weinberger NM (2005) Encoding of learned importance of sound by magnitude of representational area in primary auditory cortex. Proc Natl Adad Sci USA 102:13664-13669.

Scammell TE, Arrigoni E, Thompson MA, Ronan PJ, Saper CB, Green RW (2003) Focal deletion of adenosine A1 receptor in adult mice using an adeno-associated viral vector. J Neurosci 23(13):5762-70.

Schreiner CE, Winer JA (2007) Auditory cortex mapmaking: principles, projections, and plasticity. Neuron Rev 56:356-365. 
Schreiner CE, Polley DB (2014) Auditory map plasticity: diversity in causes and consequences. Curr Opin Neurobiol 24:143-256.

Takesian AE, Hensch TK (2013) Balancing plasticity/stability across brain development. Progress in Brain Research 207:3-34.

Thompson LF, Eltzschig HG, Ibla JC, Van De Wiele CJ, Resta R, Morote-Garcia JC, Colgan SP (2004) Crucial role for Ecto-5'-Nucleotidase (Cd73) in vascular leakage during hypoxia. J Exp Med 200:1395-1405.

Weinberger NM (1995) Dynamic regulation of receptive fields and maps in the adult sensory cortex. Annu Rev Neurosci 18:129-158.

Weinberger NM (2012) Plasticity in the primary auditory cortex, not what you think it is: implications for basic and clinical auditory neuroscience. Otolaryngol S3:002.

Wiesel TN, Hubel DH (1965) Comparison of the effects of unilateral and bilateral eye closure on cortical unit responses in kittens. J Neurophysiol 28:1029-1040.

Willot JF (1986) Effects of aging, hearing loss, and anatomical location of thresholds of inferior colliculus neurons in C57BL/6 and CBA mice. J Neurophysiol 56(2):391408.

Willot JF, Aitkin LM, McFadden SL (1993) Plasticity of auditory cortex associated with sensorineural hearing loss in adult C57BL/6 mice. J Comp Neurol 329(3):402411.

Winkler I, Kushnerenko E, Horváth J, Čeponienė R, Fellman V, Huotilainen M, Näätänen R, Sussman E (2003) Newborn infants can organize the auditory world. Proc Natl Acad Sci USA 100:11812-15.

Zhang LI, Bao S, Merzenich MM (2001) Persistent and specific influences of early acoustic environments on primary auditory cortex. Nat Neuro 4:1123-113. 


\section{VITA}

Rachel A. Chassan was born in 1989 to Shabtai and Cynthia Chassan. After receiving her high school diploma from Pine Crest School, Fort Lauderdale, Florida, she entered Rhodes College in Memphis, Tennessee. In May of 2011 she graduated with a Bachelor of Science in Chemistry. That following August, she entered the Integrated Biomedical Science program at the University of Tennessee Health Science Center, Memphis, Tennessee. In May of 2014, she will receive her Master of Science degree from the University of Tennessee. 